\title{
Cooperation Mechanisms For A Competitive, Sustainable Food Supply Chain To Reduce Greenhouse Gas Emissions
}

\section{Yashar Manteghi}

University of Kurdistan

Jamal Arkat ( $\boldsymbol{\nabla}$ j.arkat@uok.ac.ir)

University of Kurdistan https://orcid.org/0000-0002-9973-7269

Anwar Mahmoodi

University of Kurdistan

\section{Research Article}

Keywords: Food supply chain, Greenhouse gas emission, Cooperation mechanisms, Competition, Game theory, Bi-level programming

Posted Date: July 12th, 2021

DOl: https://doi.org/10.21203/rs.3.rs-612550/v1

License: (9) This work is licensed under a Creative Commons Attribution 4.0 International License. Read Full License

Version of Record: A version of this preprint was published at Environmental Science and Pollution Research on January 11th, 2022. See the published version at https://doi.org/10.1007/s11356-02117363-z. 


\title{
Cooperation mechanisms for a competitive, sustainable food supply chain to reduce greenhouse gas emissions
}

\author{
Yashar Manteghi \\ Ph.D. candidate, Department of Industrial Engineering, University of Kurdistan, Sanandaj, Iran, \\ y.manteghi@eng.uok.ac.ir \\ Jamal Arkat* \\ Associate Professor, Department of Industrial Engineering, University of Kurdistan, Sanandaj, Iran, \\ j.arkat@uok.ac.ir \\ Anwar Mahmoodi \\ Assistant Professor, Department of Industrial Engineering, University of Kurdistan, Sanandaj, Iran, \\ anwar.mahmoodi@uok.ac.ir
}

\begin{abstract}
The food industry is one of the main emitters of greenhouse gases (GHG). The consumers of this industry are aware of the unpleasant consequences of GHG emissions such as global warming and climate change, so food supply chain members should consider mechanisms to reduce GHG emissions besides economic and social goals. This paper examines the impacts of the supply chain structure and cooperation methods on the goals and decisions of a sustainable food supply chain. The proposed supply chain consists of one manufacturer and two suppliers, competition, and cooperation between those studied with centralized and decentralized structures. A single-level problem is solved for the centralized supply chain in the first scenario. The decentralized structure is then considered for the other four scenarios, and bi-level programming is used to model competition and cooperation between the members. Computational results demonstrate that the maximum total profit of the supply chain among all the decentralized scenarios is obtained with the alliance of the manufacturer and the first supplier. It is found economical to increase the budget in the scenarios where the supply chain members competed with each other. Moreover, increasing production capacity and budget reduce GHG emissions for the supply chain members forming coalitions.
\end{abstract}

Keywords: Food supply chain; Greenhouse gas emission; Cooperation mechanisms; Competition; Game theory; Bi-level programming. 


\section{Declarations}

\section{Ethics approval and consent to participate}

34 Not applicable.

\section{Consent for publication}

36 Not applicable.

37 Availability of data and materials

38 All data generated or analysed during this study are included in this published article [and its

39 supplementary information files].

40 Competing interests

41 The authors declare that they have no competing interests.

\section{Funding}

43 Not applicable.

$44 \quad$ Authors' contributions

45 Yashar Manteghi: conceptualization, investigation, methodology, writing - original draft. Jamal

46 Arkat: conceptualization, investigation. Anwar Mahmoodi: supervision, writing-review \& 47 editing.

48

49 


\section{Introduction}

51 The increase in population has led to an increase in demand for food products, and there is no balance between the production and consumption of these products due to the lack of resources, so sustainability should be considered as an essential feature of the food supply chain (MartínezGuido et al., 2018). The production of dairy products, one of the most important food products in any country's economy, leads to air pollution and waste of resources throughout the supply chain (Kirilova and Vaklieva-Bancheva, 2017). GHG emissions is one of the most tangible criteria for investigating the supply chain's environmental consequences, such as climate change and global warming. These environmental changes are harmful to man and other species, and customer awareness thereof has increased. There is greater demand for products that provide sustainability throughout the supply chain process from production to delivery to the customer. Supply chain members wish to increase demand and reduce costs by considering these issues, so all aspects of a sustainable supply chain must be considered in decision-making. Supply chain members have conflicting goals, and therefore they need to cooperate to improve their performance. Governments and related organizations are responsible for public health and must closely monitor all food supply chain processes.

Food product companies seek to maintain their competitive positions among customers by creating competitive advantages. Quality is one of the most important criteria for increasing the demand for food products besides sustainability issues. The supply chain members add additives to their products for various purposes, such as increasing demand and reducing costs. Excessive use of this type of additive may contaminate food and cause health problems for consumers. Song and Zhuang (2018) have mentioned too much melamine in dairy products by Sanlu Company in 2008, which led to kidney stones and several children's deaths. Consumer health has gained significance due to unfortunate events. Supply chain members seek to maximize their profits by abusing the lack of proper communication with the consumers, so the government and relevant organizations should monitor all the stages of the food supply chain (Song and Zhuang, 2017). Health protocols restrict the use of additives, and the government can also prevent members of the supply chain from overusing them by imposing fines.

One decision-maker makes decisions about the entire supply chain in a centralized one. In a decentralized supply chain, each member of the supply chain makes decisions based on their own goals, which may conflict with other members'. Game theory is used to model competition between decentralized supply chain members. Nash equilibrium is obtained in competition between two players with the same power (Tabrizi et al., 2018). The Stackelberg game is used where one player has more power than the others. First, the player with more power (leader) decides according to his goal and predicts the reaction of other players (followers), and the other players then react to the decision (Sharif et al., 2018). Bi-level programming is a combination of the Stackelberg game 
87 Supply chain members work together to improve their performance and the supply chain.

88 Cooperation between supply chain members can be contractual or non-contractual. Alliance and shared supply chain members in costs and revenues are mechanisms of cooperation.

In this paper, a sustainable food supply chain consisting of one manufacturer and two suppliers is studied. The manufacturer seeks to increase demand by investing in the reduction of GHG emissions. The purpose of product additives is to increase demand and reduce costs. All three economic, environmental, and social dimensions of a sustainable supply chain are considered here. This paper aims to examine the impact of the supply chain structure and relationships between the members with respect to goals and decisions. Five scenarios are presented to compare the impacts of competition and cooperation between supply chain members on their goals and decisions in centralized and decentralized structures. A centralized supply chain is considered for the first scenario, and bi-level programming is used to model the competition between supply chain members in the other scenarios.

Given the above assumptions, we seek to answer these questions.

1) What are the effects of considering different supply chain structures on supply chain members' goals and decisions?

2) What is the impact of competition between supply chain members on their goals and decisions?

3) What are the effects of the three proposed cooperation scenarios between supply chain members on their goals and decisions?

4) What share of the cost of reducing GHG emission should the second supplier have for a better effect on the supply chain members' economic and environmental goals in the fourth and fifth scenarios?

5) What are the effects of the parameters concerning each of the economic, environmental, and social dimensions of the supply chain on its other dimensions?

The rest of the article is organized as follows. In the second section, the related articles are reviewed, and the research gap is identified. The problem is described, and the objective functions and constraints for each of the supply chain members are presented in the third section. Five scenarios are investigated in the fourth part of the described problem. The solution approach is explained in the fifth section. A mathematical analysis is presented in the sixth section to examine the impacts of several important parameters and compare the decisions made by the two suppliers. In the seventh section, numerical results are presented through the solution of an example problem with the five scenarios, and sensitivity analyses are made for several important parameters. The conclusions of the study and suggestions for future research are presented in the final section. 


\section{Literature review}

The literature review consists of three subsections. In the first part, we review articles that have studied the competition and cooperation of green, sustainable supply chain members. The papers in the field of food supply chain are reviewed in the second part. The third part examines articles that use bi-level planning to model competition in the supply chain.

\subsection{Competition and cooperation in the green, sustainable supply chain}

In this section, articles in the field of competition and cooperation in the green, sustainable supply chain are reviewed. Zhou and Qin (2015) have reviewed papers on sustainable supply chain management based on game theory. The articles are reviewed in three respects: objective function, game type, and coordination. The authors conclude that a small number of articles have considered environmental and social objective functions besides the economic one, adopting multi-level models and studying the coordination mechanism along with competition. Raj et al. (2018) have investigated centralized and decentralized structures for a sustainable supply chain, including a supplier and a buyer. The Stackelberg game is used to model a decentralized supply chain. The supplier (leader) seeks to maximize its profit by determining the type of contract and green degree of the product. The buyer (follower) maximizes its profit by determining the amount of order and cooperation in the social dimension of the sustainable supply chain. Jian et al. (2019) have studied price competition between two firms in a duopoly market with different average carbon emissions per unit of homogenous products. Carbon emission regulation and cooperation mechanisms are proposed for comparison. Peng et al. (2019) have investigated the main reasons for environmental failure considering the behavioral game between government and manufacturing enterprises. Evolutionary game is used to model competition between them to implement extended producer responsibility (EPR) for e-waste. Simulation analysis is done with different strategies and improving relevant law and increasing inspection are introduced as methods to reduce environmental failures for government.

The above review shows that competition and cooperation in the sustainable supply chain have been considered in a small number of articles. Consumer health has not been considered as a social dimension of the sustainable supply chain in any of the articles. Nor has any of them considered competition and cooperation in a sustainable food supply chain.

Zhang et al. (2015) have investigated the competition and collaboration between a producer and a retailer in a product supply chain with a controllable decline rate. Decentralized and centralized scenarios are considered for the supply chain, where the producer is the leader of the Stackelberg game in the decentralized scenario. Cooperation between the retailer and the producer is considered through a revenue-sharing agreement, and the models are solved using a heuristic algorithm. Ji et al. (2017) have studied the reduction of carbon emissions in a supply chain, including a producer and a retailer. The Stackelberg game is used for modeling the decentralized 
supply chain, in which the producer is the leader. It is assumed that the consumer is interested in buying products with less GHG emissions during the supply chain operation and that the producer invests in reducing GHG. Zhu and He (2017) have investigated the impacts of competition and cooperation on the green degree of products in a supply chain, including a manufacturer and a retailer. Centralized and decentralized structures are considered there for green product design. Competition between supply chain members is based on price and green degree. Hafezalkotob (2017) has studied competition and cooperation between two green supply chains, each including a manufacturer and a retailer, along with government intervention. The manufacturer determines the wholesale price of the product and the level of energy-saving to maximize profit. The retailer maximizes profit by setting the price of the product. The government seeks to guide the supply chain members toward economic and environmental goals by setting tariff rates. The notion of coopetition is presented for the first time in that paper, in which supply chain members work together to save energy and compete on pricing strategy. Xu et al. (2019) have studied a supply chain, including one producer and one retailer, to examine the impacts of various government tax policies on the supply chain members' decisions about carbon pricing and emissions. Government policies are defined in terms of the involvement of the supply chain members in the tax policy. The Stackelberg game is used to model competition between the government (leader) and supply chain members (followers) to achieve their goals. The goal of the supply chain members and the government is to maximize profit and sustainability, respectively. Sarkar and Bhadouriya (2020) have investigated competition and cooperation between members of the bi-level supply chain. Three models are presented for a supply chain, including a retailer and several manufacturers. The centralized supply chain is investigated for the first model for the maximization of total profit. The Stackelberg game is used to address the competition between the members in the second and third models. The retailer (leader) and manufacturers (followers) seek to maximize their profits by determining the quality of green and non-green products and retail prices, respectively. The manufacturers form a coalition in the third model, and Nash equilibrium is obtained for competition between manufacturers in the second model.

Most of the above articles have studied competition between companies at different levels. Competition between different companies at the same level of the supply chain has been investigated in a smaller number of studies. GHG emission reduction, product green degree, and energy level saving have been considered as environmental criteria in various articles. A small number of articles have considered competition over price and environmental criteria simultaneously.

\subsection{Food supply chain}

This section reviews articles with the topics of quality, sustainability, and competition in the food supply chain. Ahumada and Villalobos (2009) have reviewed articles in the food and agriculture supply chain and have concluded that health, risk management, and uncertainty were less studied. 
Wang and Li (2012) have studied quality control in a milk supply chain, including a supplier and a retailer. Both members' goal is to maximize profit, and quality control is carried out in both parts of the supply chain. Centralized and decentralized structures are considered for the supply chain. In the decentralized supply chain, the Stackelberg game is used to model competition between the retailer (leader) and supplier (follower). Govindan et al. (2014) have presented a multi-objective model for locating and routing perishable food supply chains. Minimization of costs and carbon dioxide emissions are considered as objective functions for the problem. The presented model is multi-level and multi-vehicle. Kirilova and Vaklieva-Bancheva (2017) have presented a biobjective model for the green design of dairy products. The objective functions considered for the problem include the minimization of cost and GHG emission. The environmental objective function is converted into a cost objective function, and the model is solved with a single objective. Rohmer et al. (2019) have proposed a multi-objective model including cost and environmental objective functions for sustainable food supply chain network design. Various environmental dimensions, such as climate change and resource utilization, are considered for the environmental objective function. The multi-objective model is solved by the $\varepsilon$-constraint method with different criteria considered for the environmental objective function, and the results are compared. Li and Zhou (2021) have proposed a multi-objective model for a cold supply chain to improve customer satisfaction, reduce carbon emissions and minimizing costs. Dynamic and static carbon emission of supply chain is considered to determine environmental effects and a non-dominated genetic algorithm is presented to solve the proposed multi-objective model. Shirzadi et al. (2021) have proposed an inventory-routing model to optimize the total interest of agri-food reverse logistics by considering freshness quality and environmental effects. Collection and reuse of wasted products and controlling of GHG emission is considered as the environmental dimension of the green supply chain. Costs and qualities are assumed to be fuzzy, and the bipolar approach is used for fuzzy programming.

Researchers have paid more attention in recent years to the issues of quality and sustainability in the food supply chain. At most, two of the three sustainability dimensions have been investigated for the sustainable food supply chain. None of the available articles has considered all three economic, environmental, and social dimensions.

Song and Zhuang (2018) have studied the addition of additives and their health consequences in the milk supply chain. They assume that the manufacturer uses additives to increase demand, and the government prevents the overuse of these substances by imposing fines. Centralized and decentralized structures are considered for the supply chain, and the Stackelberg game is used to model competition between the government (leader) and the manufacturer (follower) to maximize profit. Song and Zhuang (2017) have proposed three models for the health issue in the milk supply chain. Centralized and decentralized structures are examined for the problem, including three players: the supplier, manufacturer, and government. In the first model, the centralized supply chain is considered to maximize the total profit of the supply chain. The decentralized structure is 
provided for the second and third models. There are coalition and competition between the supplier and the manufacturer in the second and third models. In the second model, the Stackelberg game is used to model competition between the government (leader) and coalition (follower). In the third model, the government has the greatest power among the Stackelberg game players, and the manufacturer has more power than the supplier. Zhu et al. (2018) have investigated competition between food supply chain members on the green degree of products. Centralized and decentralized structures are considered for the supply chain, including a supplier and a producer. It is assumed that the green degree of a product depends on the green degrees of the raw materials needed to produce it. The producer and supplier compete on the green degrees of the products and raw materials to maximize profit. The cost-sharing mechanism is provided to improve the performance of the supply chain members. Yu and Cruz (2019) have studied the competition between firms aimed at maximizing profit. A network model is designed for an oligopolistic industry with different environmental policies. The effects of different tax policies, such as the flat emission tax rate on the goals and decisions of the companies, are examined, and the variable inequality method is used to solve the model. Manteghi et al. (2020) have presented three models for a sustainable food supply chain, including a manufacturer and two suppliers, to study the impact of cooperation and competition between supply chain members on sustainable aspects. Centralized structure is studied for the first model and competition and cooperation is investigated in the second and third models for a decentralized supply chain.

It is concluded from the above review that health in the food supply chain is a relatively new problem. Few articles have studied competition and cooperation for the food supply chain, and none has investigated the impact of relationships between supply chain members on achieving sustainability goals.

\subsection{Bi-level programming}

In this section, we review articles that have used bi-level programming to model their problems. Yue and You (2017) have investigated the competition between members of a biofuel supply chain using bi-level programming. A heuristic algorithm is presented for solving a mixed-integer bilevel model because of the discrete variable at the lower level (follower). Saranwong and Likasiri (2017) have presented a bi-level optimization model to minimize the cost of transferring products from factories to customers. The goal of the upper level is to minimize fixed costs and the cost of transferring products from manufacturers to distributors. The goal of the lower level is to minimize the cost of transferring products from distribution centers to customers. Four algorithms are considered for solving the bi-level model, the results obtained by which are compared to each other. Golpîra et al. (2017) have presented a bi-level programming model to design a green supply chain. The goal of the upper level is to minimize the total cost of the supply chain, and the lower level is aimed at minimizing the risk of uncertainty for retailers. The KKT approach is used to convert the bi-level model to a one-level one. Wang et al. (2017) have presented a bi-level model 
for a supply chain with the goal of reducing carbon emissions. Two scenarios are defined for the problem, one of which includes more buyer power than seller power, while the other includes the opposite power distribution. A modified evolutionary algorithm is presented to solve the bi-level model because of the discrete variables at the lower level. Tabrizi et al. (2018) have studied the competition between the fish supply chain members by presenting a bi-level model. The supply chain includes several suppliers and sales centers, and there is competition between them to maximize profit. Bi-level programming is used to model the competition in which suppliers (upper level) have more power than sales centers (lower level). The suppliers and the sales centers compete with each other at the same level. Nash equilibrium is obtained for the optimal value of supply and inventory policy for the upper level and the inventory of the sales center for the lower level. The particle swarm optimization (PSO) algorithm is used to solve the problem. Safaei et al. (2018) have presented a robust bi-level optimization model for the relief supply chain. The transshipment relief points constitute the upper level of the model to minimize costs. Risk minimization is the goal of the supplier relief points, making up the lower level of the model. The scenario-based approach is used to consider uncertainty. The bi-level model is converted to a single-level model using the KKT conditions. Sharif et al. (2018) have presented a multi-product bi-level model to maximize the profits of the municipality and buyers. The municipality decides on network design, pricing, outsourcing, bidding, and company selection to maximize its profits at the upper level. The buyers determine price at the lower level to maximize their profits. A heuristic approach is presented to solve the mixed-integer bi-level model, the results of which are compared to those of the KKT method. In most research, there is a single decision-maker for the upper and lower levels of bi-level programming.

\subsection{Research gap}

According to the above review, health is a new issue for the food supply chain. Additives and GHG emissions are both harmful to consumer health, and none of the researchers has investigated them as social and environmental criteria for a sustainable supply chain. Nor has any of them considered all the three economic, environmental, and social dimensions for such a supply chain. According to Table (1), centralized and decentralized structures have been studied for the supply chains in most articles to enable comparison. Competition between supply chain members at the same level has been studied in a few of them. Comparing different scenarios of cooperation, such as alliance and cost-sharing, is useful for providing management suggestions. A few researchers have considered cooperation as a mechanism for improving the performance of supply chain members besides the competition. Manteghi et al. (2020) have investigated the impacts of supply chain structure and competition and cooperation between members in achieving the goals of a sustainable food supply chain. They have used game theory to model competition between supply chain members, and the alliance is considered a cooperation mechanism in this paper. The use of additives and emissions should be limited in practice, and bi-level programming is used to model 
competition between supply chain members. Bi-level programming combines the Stackelberg game and mathematical modeling, and few of the papers have used it for the above purpose.

This paper studies the competition and cooperation between members of a dairy supply chain, including one manufacturer and two suppliers. The reduction of GHG emissions and the use of additives are considered as competitive advantages, and prices can increase the demand for food products, thereby playing an important role in public health and achievement of the economic goals of the supply chain members. All three economic, environmental, and social dimensions of the supply chain must be considered to improve the members' performance in the long term. Five scenarios are considered in this paper to compare the impacts of competition and cooperation between supply chain members on their goals and decisions. A single-level model is presented for a centralized supply chain in the first scenario. Bi-level programming is used in other scenarios to model competition between members of a decentralized supply chain. Alliance and cost-sharing are considered as mechanisms for cooperation between members of the supply chain in the third to fifth scenarios.

Table (1) Comparison of the major papers mentioned in the literature review

\begin{tabular}{|c|c|c|c|c|c|c|c|c|c|c|c|}
\hline & \multicolumn{2}{|c|}{ Structure } & \multicolumn{2}{|c|}{ Sustainability } & \multicolumn{2}{|c|}{ Competition } & \multicolumn{2}{|c|}{ Cooperation } & \multicolumn{3}{|c|}{ Modeling } \\
\hline & 胥 & 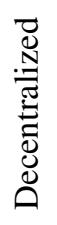 & 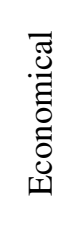 & 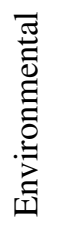 & 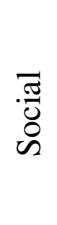 & $\begin{array}{l}\text { ज̃ } \\
\text { Z } \\
\text { Z }\end{array}$ & 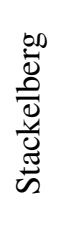 & & 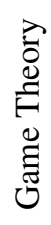 & 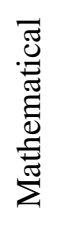 & 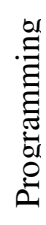 \\
\hline Ji et al. (2017) & & $*$ & $*$ & $*$ & & & $*$ & & $*$ & & \\
\hline Golpîra et al. (2017) & & $*$ & $*$ & $*$ & & & $*$ & & $*$ & $*$ & \\
\hline Song and Zhuang (2017) & $*$ & $*$ & $*$ & & $*$ & & $*$ & $*$ & $*$ & & \\
\hline Song and Zhuang (2018) & $*$ & $*$ & $*$ & & $*$ & & $*$ & & $*$ & & \\
\hline Sharif et al. (2018) & & $*$ & $*$ & $*$ & & & $*$ & & $*$ & * & \\
\hline Zhu et al. (2018) & $*$ & $*$ & $*$ & $*$ & & & $*$ & $*$ & $*$ & & \\
\hline Tabrizi et al. (2018) & & $*$ & $*$ & & & $*$ & $*$ & & $*$ & $*$ & \\
\hline Raj et al. (2018) & $*$ & $*$ & $*$ & $*$ & $*$ & & $*$ & $*$ & $*$ & & \\
\hline Rohmer et al. (2019) & & $*$ & $*$ & $*$ & & & & & & $*$ & \\
\hline Sarkar and Bhadouriya (2020) & $*$ & $*$ & $*$ & $*$ & & & $*$ & $*$ & $*$ & & \\
\hline Manteghi et al. (2020) & $*$ & $*$ & $*$ & $*$ & $*$ & & $*$ & $*$ & $*$ & & \\
\hline Current research & $*$ & $*$ & $*$ & $*$ & $*$ & $*$ & $*$ & $*$ & $*$ & $*$ & \\
\hline
\end{tabular}




\section{Problem definition}

323 The manufacture of products emits GHG, and the negative impacts of GHG emissions on the environment and health of living organisms are evident. The manufacturer increases its costs by investing in the reduction of GHG emissions. Additives are added to products by the manufacturer for purposes such as increasing revenue and reducing costs. Excessive use of additives may be harmful to consumers' health, so supply chain members or external inspectors should control the process. The government can also impose fines to prevent the overuse of substances. The reduction of GHG and the use of additives affect public health, environmental goals, and supply chain member profits, so decisions about them must be made simultaneously.

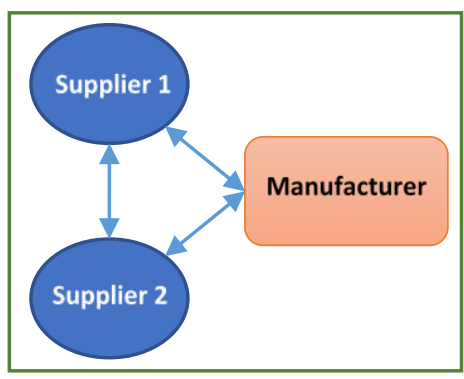

(a)

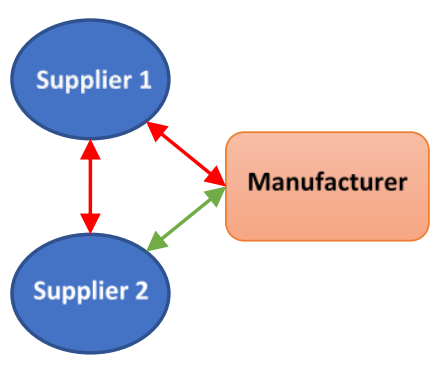

(d)

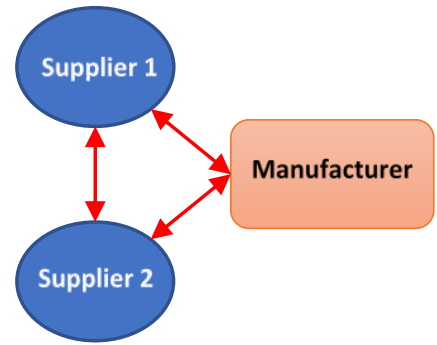

(b)

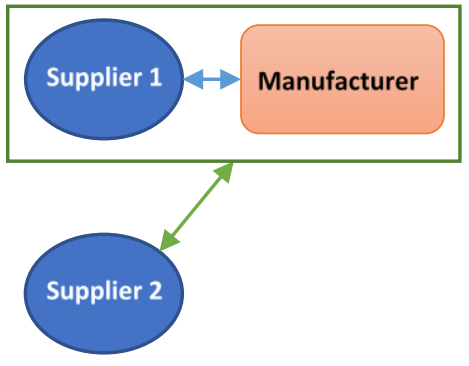

(e)

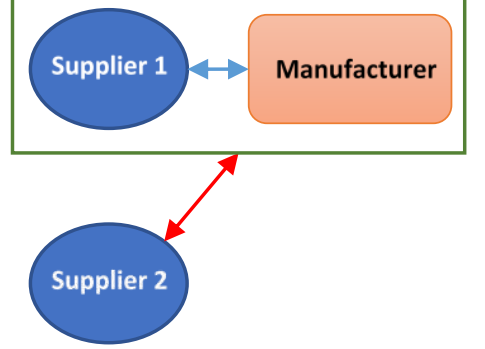

(c)

$\longleftrightarrow$ Cooperation

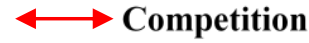

$\longleftrightarrow$ Cooperation-Competition

Figure (1) Centralized (a) and decentralized (b, c, d) proposed scenarios

This paper investigates a bi-level supply chain of dairy products, including one manufacturer and two suppliers. In the examined problem, the manufacturer aims to maximize profit by determining the reduction of GHG emissions and the percentage of additives as well as prices. The suppliers compete with each other to maximize their profits by setting the prices of raw materials. Centralized and decentralized structures are considered for the problem, the impacts of which on the goals and variables of the problem are investigated. The centralized supply chain is considered in the first scenario, and the structures in the other four scenarios are decentralized. In the second scenario, there is competition between members of the supply chain to maximize profit. Cooperation between supply chain members is considered besides the competition in the third to 
342 fifth scenarios. In the third scenario, an alliance is formed between the manufacturer and the first

343 supplier. The second supplier cooperates with the manufacturer in the fourth scenario by sharing 344 the cost of reducing GHG emissions with the first supplier. In the fifth scenario, the first supplier

345 allies with the manufacturer, and the second cooperates with it to decrease the cost of reducing 346 GHG emissions. A schematic of the five scenarios is shown in Figure 1. Bi-level programming is 347 used in the second to fifth scenarios to model competition and cooperation between the 348 manufacturer and suppliers.

349 In this paper, the manufacturer produces two substitutable products with a share of the market 350 demand of $\mu_{i}$. The value of the customer demand function for each product depends on its price, 351 and the product demand decreases by $\alpha$ for each unit of increase in the product price. The products 352 are substitutable, so the demand for each increases by $\delta$, increasing the price of each unit of the 353 other product. The demand for each product is a function of the percentage of additives and 354 reduced GHG emissions besides the price. An increase in the percentage of additives improves the 355 appearance of the product and increases its demand. Customers are environmentally conscious; 356 therefore, the demand for products with lower GHG emissions is higher. The demand function is 357 presented in Relation (1), common in the research literature (Ji et al., 2017; Zhu et al., 2018). One 358 unit of raw materials is required for the manufacture of each unit of product, and Supplier 1 and 359 Supplier 2 are responsible for the preparation of the raw materials for production of the first and 360 second products, respectively, so the index $i$ is used only for the product. The symbols in Relation 361 (1) are described in the Definition of Symbols section.

$$
d_{i}=\mu_{i} \bar{d}-\alpha p_{i}+\delta p_{3-i}+\beta x+\gamma \Delta \quad, \quad \forall i
$$

\section{Index}

$363 \quad i$ : Product $(i=1,2)$

364 Parameters

$365 g:$ Government penalty for endangerment of consumer health

$366 f$ : Cost of using one percent additive in one unit of milk $(1 \mathrm{~kg})$

$367 m$ : Cost of using one percent protein in one unit of milk $(1 \mathrm{~kg})$

$368 \mathrm{~s}_{i}$ : Supplier capacity of raw materials for product $i$

$369 u$ : Maximum allowable additives used in one unit of product

$370 \phi$ : Density of nitrogen in one percent of the additive

$371 \quad o:$ Density of nitrogen in one percent of protein

$372 n$ : Minimum amount of nitrogen required in the product 
$373 \rho$ : Second supplier's share of the cost of reduction of GHG emission

$374 \theta$ : Slope for the probability of endangering consumer health

$375 r$ : Cost of one-unit reduction of GHG emission

$376 \tau$ : Capacity of the manufacturer

$377 \sigma_{i}:$ Cost of manufacture of one unit of product $i$

$378 c_{i}$ : Cost of supply of raw materials for the manufacture of one unit of product $i$

$379 k$ : Cost of one unit of reduction of GHG emission

$380 \quad B$ : Budget of the manufacturer

$381 E$ : Maximum allowable GHG emissions

$382 \bar{d}$ : Market base of the product

$383 \alpha$ : Self-price sensitivity coefficient of demand

$384 \delta$ : Cross-price sensitivity coefficient of demand

$385 \quad \beta$ :Demand sensitivity to one unit of reduction of GHG emission

$386 \gamma$ :Demand sensitivity to one percent of the additive

$387 e$ : Volume of GHG emitted through the manufacture of one unit of product

$388 \quad \mu_{i}$ : Market-based share of product $i$

$389 \quad$ Variables

$390 \quad p_{i}$ : Price of product $i$

$391 \quad v_{i}$ : Margin profit of product $i$

$392 x$ : Reduction of GHG emission

$393 w_{i}$ : Wholesale price of raw materials used in one unit of product $i$

$394 \Delta$ : Percentage of additive in one unit of product

$395 \quad l$ : Percentage of protein in one unit of product

396 Function

$397 \quad H$ : Probability of endangering consumer health

$398 d_{i}$ : Demand function of product $i$ 
In this problem, the goal of each supply chain member is to maximize its profit, which results from the difference between income and costs. Manufacturer costs include production costs, the cost of investment in clean technologies to reduce GHG emissions, and the cost of purchasing raw

402

403

404

405

406

407

408

409

410

411

412

413

414

415

416

417

418

419

420

421

422 materials from the suppliers. It is assumed that the manufacturer produces dairy products, and the cost of using protein in these products is $m l$. The manufacturer uses melamine instead of protein to reduce costs and increase demand, and the cost of using melamine is $f \Delta$. According to the protocols, the percentage of melamine used should not exceed a certain amount, which is considered a constraint in the problem. Excessive use of melamine causes health problems for consumers, so the government prohibits its overuse by imposing $g H$ of fines to the manufacturer. The production process emits GHG at a social cost of $k(e-x)$. The demand for products with lower GHG emissions is higher, as mentioned in the previous section, so the manufacturer seeks to invest in modern, useful technologies to reduce GHG emissions. The reduction requires longterm investment, costing $r x^{2}$ according to related articles. Governments and private organizations adopt strict rules on maximum GHG emissions, regarded as a constraint in the model. The manufacturer also has a budget limit to pay for fines incurred due to the use of additives, GHG emission, and purchase of raw materials.

The suppliers seek to maximize their profits by setting initial prices for raw materials, directly impacting the prices of and the demand for the products, and the raw materials needed to manufacture a product increase as product demand rises. Each supplier is responsible for supplying one of the products. Strictly, the first and second suppliers are in charge of supplying the raw materials needed to manufacture the first and second products, respectively, and capacity limitations are involved in supplying raw materials. The mathematical models for the manufacturer and the suppliers are presented in the following sections.

\section{Manufacturer model}

$$
\begin{aligned}
& \max Z_{m}=\sum_{i} d_{i}\left(p_{i}-w_{i}-\sigma_{i}-k(e-x)-m l-f \Delta-g H\right)-r x^{2} \\
& p_{i}=w_{i}+v_{i}, \quad \forall i \\
& \phi \Delta+o l \geq n \\
& H=\theta \Delta \\
& \Delta \leq u \\
& \sum_{i} d_{i} \leq \tau \\
& x \leq e \\
& \sum_{i}(e-x) d_{i} \leq E
\end{aligned}
$$




$$
\begin{aligned}
& \sum_{i} w_{i} d_{i}+\sum_{i}+g H d_{i}+r x^{2} \leq B \\
& p_{i}, v_{i}, x, \Delta, l \geq 0
\end{aligned}
$$

423 Relation (2) defines the objective function of the manufacturer. Product price is the sum of the profit margins considered by the manufacturer and the price of the raw materials, presented in Relation (3). Products are tested for quality throughout the process, where they must exhibit a minimum amount of protein. The percentage of nitrogen in a dairy product is measured to determine the amount of protein. In this paper, it is assumed that the manufacturer uses additives instead of protein to reduce costs. Each unit of dairy product must contain the minimum amount of nitrogen, presented in Relation (4). Consumption of additives may be detrimental to consumer health, and the government is assumed to impose fines on the endangerment of consumer health. The health probability function represents the social dimension of the problem, which depends on the percentage of additives used (Song and Zhuang, 2017, 2018). The probability function of health risk is linearly dependent on the percentage of additives in the problem, as presented in Relation (5). It is not enough to consider a fine on additives, the amount of which should not exceed the set limit, indicated by Relation (6). Relation (7) shows the limit on manufacturer capacity for both types of products. Relation (8) indicates that the maximum reduction of GHG emissions is as much as the amount of emission from the manufacture. Relations (9) and (10) determine budget constraints and maximum GHG emissions. The type of manufacturer variable is specified in Relation (11).

\section{Supplier model}

$$
\begin{array}{ll}
\max Z_{S_{i}}= & \left.w_{i}-c_{i}\right) d_{i} \\
d_{i} \leq s_{i} & , \quad \forall i \\
w_{i} \geq 0 & , \quad \forall i
\end{array}
$$

441 Relation (12) defines the objective function of each supplier. The amount of raw materials supplied 442 by each supplier is limited, and Relation (13) specifies the maximum capacity of each supplier. 443 Relation (14) identifies the type of variable of each supplier.

\section{Competition and cooperation} In this section, the relationships between the supply chain members are studied in five scenarios. In the first scenario, the supply chain is assumed to be centralized, and a decision-maker decides about the entire supply chain to maximize total profit. It is assumed that each supply chain member decides to maximize its profit in the second scenario. This scenario investigates vertical 
suppliers. The first supplier forms an alliance with the manufacturer in the third scenario to improve the supply chain goals in manufacturing the first product. The second supplier's share of reducing GHG emissions is considered a mechanism of cooperation in the fourth model besides competition between the supply chain members. In the fifth scenario, both suppliers cooperate with the manufacturer. The first supplier forms an alliance with the manufacturer, and the second one shares the cost of reducing GHG emissions. The above scenarios are considered to investigate the effect of the supply chain structure and the type of relationship between the chain members on the goals and decisions. Centralized and decentralized scenarios are presented for the problem and lemmas for solving the second to fifth scenarios.

\subsection{Cooperation}

In the first scenario, it is assumed that a single decision-maker decides about the entire supply chain. This scenario is considered an ideal case compared to the others and is less common in practice. The decision-maker aims to maximize the total profit of the supply chain by determining product prices, the percentage of melamine, the percentage of protein, and the reduction of GHG emissions. The objective function in this scenario is the sum of those of the supply chain members, as presented in Relation (15).

$$
\max Z_{c}=Z_{m}+\sum_{i} Z_{S_{i}}=\sum_{i} d_{i}\left(p_{i}-c_{i}-\sigma_{i}-k(e-x)-m l-f \Delta-g H\right)-r x^{2}
$$

Subject to $(4,5,6,7,8,9,10,11,13,14)$

The decision-maker in the centralized model does not need to determine the price of raw materials and profit margins, so Relation (3) does not apply to this model. In this scenario, the relationships between the supply chain members are not considered, and the proposed model is single-level. The solution of a single-level model does not involve the complexities of solving a bi-level model. It is appropriate to consider a centralized supply chain for economic purposes (supply chain profit). Still, it is necessary to study the effect of a centralized structure on the environmental and social dimensions of a sustainable supply chain.

\subsection{Decentralized competition}

According to Relations (2) and (12), the suppliers' income is considered a cost incurred by the manufacturer, so the manufacturer seeks to supply the raw materials at the lowest price. In this scenario, there is competition (vertical) between the manufacturer and suppliers to maximize profit. The manufacturer seeks to maximize its profit by determining the profit margin, percentage of additives, percentage of protein, and reduction of GHG emissions. Each supplier is responsible for supplying the necessary raw materials for one type of product, and the price of the raw materials supplied by the suppliers affects the demand for the product according to Relations (1) and (3). 
According to Relation (7), production capacity is limited, so there is a competition between the suppliers to maximize profit. Nash equilibrium is obtained for the competition between the suppliers. Bi-level programming is used for considering the competition between the manufacturer (leader) and the suppliers (followers), as presented below.

$$
\max Z_{m}=\sum_{i} d_{i}\left(p_{i}-w_{i}-\sigma_{i}-k(e-x)-m l-f \Delta-g H\right)-r x^{2}
$$

Subject to $\quad(3,4,5,6,7,8,9,10,11)$

$$
\max Z_{S_{i}}=\left(w_{i}-c_{i}\right) d_{i} \quad(i=1,2)
$$

Subject to $(13,14)$

The existence and uniqueness of the Nash equilibrium obtained for the suppliers must be proven. First, lemma (1) is used to demonstrate that the Nash equilibrium between the two suppliers obtains at least one solution, and the uniqueness of the Nash equilibrium is then proven in lemma (2).

Lemma 1: The game between the suppliers to determine wholesale price involves at least one Nash equilibrium.

Lemma 2: The game between the suppliers to determine wholesale price involves exactly one Nash equilibrium.

Proofs for lemmas (1) and (2) are presented in Appendices (1) and (2), respectively.

\subsection{Alliance between the manufacturer and the first supplier}

In this scenario, it is assumed that the manufacturer allies with the first supplier. The alliance seeks to maximize the profits of the coalition members by determining the price of the first product, profit margin of the second product, percentage of additives, percentage of protein, and reduction of GHG emissions. The second supplier competes with the coalition by setting the wholesale price of the raw materials of the second product to maximize its profit. Bi-level programming is used to model the competition between the alliance (leader) and the second supplier (follower). The first supplier is responsible for providing the first product's raw materials, so the coalition can increase its demand by setting a lower price for the first product. The second supplier seeks to increase the price of raw materials for the second product due to the competition with the coalition members, which leads to a decrease in demand for the second product. The alliance's profit is presented in Relation (16), and Relation (3) in the third scenario is considered only for the second product. The bi-level programming model of the third scenario is presented below.

$$
\begin{aligned}
\max Z_{C o}=Z_{m} & +Z_{S_{1}} \\
& =d_{1}\left(p_{1}-c_{1}-\sigma_{1}-k(e-x)-m l-f \Delta-g H\right) \\
& +d_{2}\left(p_{2}-w_{2}-\sigma_{2}-k(e-x)-m l-f \Delta-g H\right)-r x^{2}
\end{aligned}
$$

Subject to $\quad(3,4,5,6,7,8,9,10,11,13,14)$ 


$$
\begin{aligned}
& \max Z_{S_{2}}=\left(w_{2}-c_{2}\right) d_{2} \\
& \text { Subject to }(13,14)
\end{aligned}
$$

$$
\max Z_{m}=\sum_{i} d_{i}\left(p_{i}-w_{i}-\sigma_{i}-k(e-x)-m l-f \Delta-g H\right)-(1-\rho) r x^{2}
$$

Subject to

$$
\begin{aligned}
& (3,4,5,6,7,8,9,10,11) \\
& \max Z_{S_{1}}=\left(w_{1}-c_{1}\right) d_{1}
\end{aligned}
$$$$
\text { Subject to }(13,14)
$$$$
\max Z_{S_{2}}=\left(w_{2}-c_{2}\right) d_{2}-\rho \operatorname{rr} x^{2}
$$

Subject to $(13,14)$

523 Lemma (3) proves that the Nash equilibrium between the suppliers provides at least one answer 524 for the fourth scenario. The uniqueness of that solution in the fourth model is proven in lemma (4). Lemma 3: The game between the suppliers in the fourth scenario has at least one Nash 526 equilibrium.

527 Lemma 4: The game between the suppliers in the fourth scenario has exactly one Nash 528 equilibrium.

529 Proofs for lemmas (3) and (4) are presented in Appendices (3) and (4), respectively. 


\subsection{Alliance with the first supplier and cooperation mechanism for the second}

In this scenario, the first supplier forms an alliance with the manufacturer, and the second supplier shares the cost of reducing GHG emissions. The coalition members compete with the second supplier, and their goal is to maximize the profit of the coalition by determining the price of the first product, profit margin of the second product, percentage of melamine, percentage of protein, and reduction of GHG emission. The second supplier's goal is to maximize its profit by setting the wholesale price of the raw materials of the second product. There are two types of mechanisms for cooperation in this scenario. The manufacturer seeks to reduce the price of and increase the first product demand by allying with the first supplier, as in the third scenario. In the second mechanism, the second supplier shares the cost of reducing GHG emissions by the manufacturer to increase the demand for the products and reduce GHG emissions, as in the fourth scenario. The coalition's profits and the second supplier are presented in Relations (19) and (20), respectively. Relation (3) is considered in the fifth scenario only for the second product, and the bi-level programming model of the scenario is presented below.

$$
\begin{aligned}
& \max Z_{C o}=Z_{m}+Z_{S_{1}}=d_{1}\left(p_{1}-c_{1}-\sigma_{1}-k(e-x)-m l-f \Delta-g H\right)+ \\
& d_{2}\left(p_{2}-w_{2}-\sigma_{2}-k(e-x)-m l-f \Delta-g H\right)-(1-\rho) r x^{2}
\end{aligned}
$$

Subject to $\quad(3,4,5,6,7,8,9,10,11,13,14)$

$$
\max Z_{S_{2}}=\left(w_{2}-c_{2}\right) d_{2}-\rho r x^{2}
$$

Subject to $(13,14)$

\section{Mathematical analysis}

The suppliers affect the manufacturer's decisions and goals and the supply chain by determining the wholesale price of the raw materials. This section assumes that the suppliers have sufficient capacity to supply raw materials for the products, and Relation (13) is not considered. The effects of the self-price and cross-price sensitivity coefficients of demand on the wholesale price of raw materials, product demand, and the suppliers' profits are investigated first for the second to fourth scenarios. Then, the raw material prices, demand, and prices of the first and second products in the second to fifth scenarios are compared.

Proposition 1: In the second and fourth scenarios,

1) $\frac{\partial w_{1}}{\partial \alpha} \leq 0, \frac{\partial w_{2}}{\partial \alpha} \leq 0$

2) $\frac{\partial Z_{S_{1}}}{\partial \alpha} \leq 0, \frac{\partial Z_{S_{2}}}{\partial \alpha} \leq 0$.

3) $\frac{\partial w_{1}}{\partial \delta} \geq 0, \frac{\partial w_{2}}{\partial \delta} \geq 0$.

4) $\frac{\partial Z_{S_{1}}}{\partial \delta} \geq 0, \frac{\partial Z_{S_{2}}}{\partial \delta} \geq 0$. 
A proof for proposition (1) is presented in Appendix (5).

The manufacturer seeks to reduce the product price by increasing the dependence of demand on the price to prevent a sharp decline in the demand for the products. The suppliers try to avoid a sharp drop in profit due to the decrease in demand by lowering raw material prices. The suppliers' profits also decrease as the prices of their raw materials decrease. The suppliers can prevent a drop in product demand and profit by contributing to other production costs, such as government fines for using melamine and the cost of reducing GHG emissions. Competition over price increases with the increasing dependence of product demand on the price of the other product. The manufacturer can increase the prices of its products without reducing demand by increasing competitiveness. The suppliers can also increase the price of raw materials by increasing their products' prices, and their profits also increase with an increase in the price of raw materials. They can increase their profits by setting high prices for raw materials where price competitiveness is high. It is concluded that the suppliers' knowledge of the product market is necessary for determining the appropriate pricing strategy.

Proposition 2: In the second and fourth scenarios,

1) If $\frac{\bar{d}\left(\mu_{2}-\mu_{1}\right)+\alpha\left(c_{2}-c_{1}\right)}{\alpha+\delta} \geq v_{2}-v_{1}$ then $w_{2} \geq w_{1}$; otherwise $w_{2}<w_{1}$.

2) If $\frac{\bar{d}\left(\mu_{2}-\mu_{1}\right)}{\alpha+\delta}+c_{1}-c_{2} \geq v_{2}-v_{1}$ then $d_{2} \geq d_{1}$; otherwise $d_{2}<d_{1}$.

A proof for proposition (2) is presented in Appendix (6).

The demand for each product increases with the reduction of its profit margin concerning that of the other product. The price of raw materials increases with an increase in demand. The manufacturer must consider the impact of the decision on the product market and the goals of the other members of the supply chain before determining the profit margins for their products. The demand for each product increases with an increasing market share, and the suppliers can increase the prices of their raw materials by increasing demand. An increase in the cost of supply increases the price of raw materials, and the demand for the products decreases with an increase in their prices. The suppliers' profits increase with increases in the shares of the products and decreases in the costs of supply. Product type is very important in the manufacturer's and suppliers' specifications of the pricing strategy. Competition on pricing increases with the increasing dependence of price demand, so the manufacturer cannot sell a product with a high price difference to avoid a sharp drop in demand. The dairy market is always changing for reasons such as the arrival of new products and changing customer tastes, so companies can compete in the market to make the right decisions in the shortest times.

Proposition 3: In the third and fifth scenarios,
1) $\frac{\partial w_{2}}{\partial \alpha} \leq 0, \frac{\partial Z_{S_{2}}}{\partial \alpha} \leq 0$. 
2) $\frac{\partial w_{2}}{\partial \delta} \geq 0, \frac{\partial Z_{S_{2}}}{\partial \delta} \geq 0$.

592 A proof for proposition (3) is presented in Appendix (7).

593 In the third and fifth scenarios, the manufacturer and first supplier form an alliance with each other and seek to maximize their demand and profits by reducing the price of the first product. As in 595 proposition (1), the coalition members seek to reduce the product prices to prevent a sharp drop in demand by increasing its dependence on price. The second supplier also reduces the price of its raw materials to avoid a sharp decline in profit, increasing the dependence of demand on the product prices. The second supplier's profit decreases with a reduction in the price of raw materials. Product price competitiveness increases with an increase in the dependence of product demand on the price of the other product. The second supplier seeks to increase the product price by increasing competitiveness, leading to an increase in the price of raw materials and the profit of the second supplier. The coalition members seek to reduce the price of the first product to increase the demand for it and their profits, and it is not possible to drastically reduce the price of the first product by increasing competitiveness. The price difference between the products decreases with increasing competitiveness. In the third scenario, the second supplier can share the cost of reducing GHG emissions to increase the demand for the second product, as in the fifth scenario, and more raw materials are therefore needed. In the fifth scenario, the cost of reducing GHG emissions and the second supplier's share thereof are important.

Proposition 4: In the third and fifth scenarios,

1) If $p_{1}(2 \alpha-\delta)-\alpha v_{2} \geq \mu_{2} \bar{d}+\beta x+\gamma \Delta+\alpha c_{2}$ then $p_{1} \geq p_{2}$; otherwise $p_{1}<p_{2}$.

2) If $p_{1}(2 \alpha-\delta)(\alpha+\delta)-\alpha(\alpha-\delta) v_{2} \geq \epsilon$ then $d_{2} \geq d_{1}$; otherwise $d_{2}<d_{1}$.

612 Where $\epsilon=\alpha^{2} c_{2}+(\alpha+\delta)(\beta x+\gamma \Delta)+\bar{d}\left(2 \mu_{1} \alpha+\mu_{2}(\alpha-\delta)\right)$.

613 A proof for proposition (4) is presented in Appendix (8).

614 The alliance between the producer and the first supplier would be expected to reduce the price of 615 the first product, which is higher than the price of the second product, however, under the 616 conditions mentioned above. The price difference between the two products would decrease with 617 a reduction of the second product's share of the market and lower effects of emissions and 618 melamine on demand. A reduction of the price difference between the products leads to decreases 619 in the demand for the first product and the coalition members' profits, so the coalition must decide 620 with knowledge of market conditions and product type. It seems unlikely that the demand for the 621 second product will be higher than that of the first product according to obtained results. 


\section{Solution method}

623 Competition between the supply chain members is considered in the second to fifth scenarios assumed for the problem. The Nash game between the suppliers has a unique answer, given

625

626

627

628

629

630

631

632

633

634

635

636

637

638

639

640

641

642

643

$$
\begin{aligned}
& L_{i}=Z_{S_{i}}-\lambda_{i}\left(d_{i}-s_{i}\right) \quad, \quad \forall i \\
& \mu_{i} \bar{d}+\beta x+\gamma \Delta+\alpha\left(c_{i}+\lambda_{i}-v_{i}-2 w_{i}\right)+\delta\left(v_{3-i}+w_{3-i}\right)=0, \quad \forall i \\
& \lambda_{i}\left(d_{i}-s_{i}\right)=0, \quad \forall i
\end{aligned}
$$

644 Relations (22) and (23) are considered for each supplier and added to the upper-level constraints to convert the bi-level models to single-level ones in the second to fifth scenarios. The objective functions for the scenarios are nonlinear, and so are some of their constraints.

\section{Numerical results}

649

In this section, a numerical example of a real case is considered to investigate the practical 650 applications of the scenarios presented in the previous section. The information provided in this section is taken from Song and Zhuang (2018). The dairy supply chain is considered in this paper, 
where quality control is very important for the products. The percentage of protein in each product is measured for that purpose. The density of nitrogen in the protein is $16 \%$, and the amount of nitrogen in one kilogram of the dairy product is measured to determine its protein amount, which must be at least .0228 . The cost of using protein is $.84 \frac{\mathrm{RMB}}{\mathrm{kg}}$. The density of nitrogen in melamine is .666 , which is higher than that in protein, and the cost of using melamine is $.7 \frac{\mathrm{RMB}}{\mathrm{kg}}$, which is lower than the cost of using protein. The manufacturer uses melamine instead of protein to reduce costs and increase demand, but excessive melamine use causes health problems. In this paper, it is assumed that the probability of endangering health is linearly dependent on the percentage of melamine, and $\theta$ is estimated to be 106.3. The government has imposed a fine of 1,500 to prevent the manufacturer from using too much melamine, the maximum allowable amount of which to be used in the products is .0001 . The carbon dioxide emission from the production of each unit of a dairy product is $1214 \frac{d c^{3} \mathrm{Co} 2}{\mathrm{~kg}}$ (Food and Organization, 2010). The social cost of GHG emissions is $.0007 \frac{R M B}{d c^{3} \mathrm{Co} 2}$ (Gillingham and Stock, 2018), and the manufacturer seeks to reduce GHG emissions to increase demand. The values of the other parameters are estimated according to experts' opinions and the values obtained from the previous articles. The first scenario involves a single-level model, and the others turn into single-level models using KKT conditions. The objective function is nonlinear in all the scenarios, as are some of the constraints. All the scenarios are solved in the GAMS software with the BARON solver.

The impacts of the different scenarios on the supply chain members' decisions and different goals of a sustainable supply chain are studied in Section 7.1. The second supplier shares the cost of reducing GHG emissions in the fourth and fifth scenarios. The effect on the goals and decisions of the supply chain members is examined in Section 7.2. The impacts of four parameters, including the total budget, manufacturer's capacity, government penalty for endangerment of consumer health, and cost of reduction of GHG emission, on the goals and decisions of the supply chain members, are investigated in Sections 7.3 to 7.6 , respectively.

\subsection{Comparison of the scenarios}

The optimal values of the variables for all the five scenarios and those of the objective functions of the supply chain members and the total profit of the supply chain are presented in Tables (2) and (3), respectively. On that basis, the total profit of the supply chain is greater in the centralized scenario than in the others, and GHG emission is the least there. The alliance between the manufacturer and the first supplier in the third scenario provides the greatest total supply chain profit among the decentralized scenarios. The coalition members tend to reduce GHG emission and increase demand in the fifth scenario by having the second supplier share the costs, but the increase in revenue due to increased demand is less than the increase in the cost of reducing GHG emissions; therefore, total supply chain profit is less in this scenario than in the third. This feature 
is also evident in comparing total supply chain profit in the second and fourth scenarios. It would not be economical in the fourth and fifth scenarios to have the second supplier share the cost of reducing GHG emissions. The GHG emissions in the fifth scenario are the lowest among those in the decentralized scenarios, and those in the fourth scenario are lower than those in the second. Hence, it is environmentally appropriate for the second supplier to share the cost of reducing GHG emissions. The difference in total supply chain profit between the third and fifth scenarios is less than the difference between them in GHG emissions, so the fifth scenario is the most suitable among the decentralized structures to balance the economic and environmental goals of the sustainable supply chain. The supply chain members must decide how to cooperate with each other according to the priority of economic and environmental goals in general. $r$ (cost of reduction of GHG emission) is another important factor in the members' decision-making in cooperation with each other, and they are more willing to cooperate by reducing the parameter. It can be concluded from Table (3) through comparison of the second and third scenarios and of the fourth and fifth scenarios that the profit of the second supplier in the alliance between the manufacturer and first supplier is greater than that in the competition between them. In all five scenarios, the percentage of additives used is the same and equal to zero. According to Table (2), product price is higher in the second and fourth scenarios than in the others because of the competition between the supply chain members, so the products' demand is less in these scenarios than in the others. The price of raw materials required for the first product is higher than that for the second product in all five scenarios because the cost of raw materials and supply capacity for the first product are higher than those for the second product. The first product price is higher than that of the second because the price of raw materials required for the first product is higher.

Table (2) Optimal values of the decision variables

\begin{tabular}{cccccccccc}
\hline Scenario & $l$ & $\Delta$ & $x$ & $p_{1}$ & $p_{2}$ & $d_{1}$ & $d_{2}$ & $w_{1}$ & $w_{2}$ \\
\hline 1 & 0.18 & 0 & 958.98 & 53.59 & 43.71 & 200000 & 158753 & & \\
2 & 0.18 & 0 & 217.63 & 74.60 & 62.40 & 90428 & 72248 & 13.07 & 10.45 \\
3 & 0.18 & 0 & 762.51 & 57.87 & 55.35 & 200000 & 85256 & & 12.28 \\
4 & 0.18 & 0 & 267.48 & 74.99 & 62.77 & 90080 & 72247 & 13.02 & 10.42 \\
5 & 0.18 & 0 & 941.28 & 58.89 & 56.24 & 200000 & 86540 & & 12.46 \\
\hline
\end{tabular}

Table (3) Optimal values of the objective functions

\begin{tabular}{cccccc}
\hline Scenario & $Z_{S_{1}}$ & $Z_{S_{2}}$ & $Z_{M}$ & $Z_{M}+Z_{S_{1}}$ & $Z_{M}+Z_{S_{1}}+Z_{S_{2}}$ \\
\hline 1 & & & & & 16117740 \\
2 & 1168196.12 & 749429 & 9046404.96 & & 10964020 \\
3 & & 1038369.2 & & 14821222.98 & 15222580 \\
4 & 1159200 & 727052.089 & 9076883.91 & & 10963140 \\
5 & & 839529.739 & & 14374099.49 & 15213630 \\
\hline
\end{tabular}




\subsection{Effect of the second supplier's share of the cost of reduction of GHG emission}

711 This section investigates the effects of $\rho$ on the supply chain members' variables and objective 712 functions in the fourth and fifth scenarios. As shown in Table (4), the manufacturer's incentive to 713 reduce GHG emissions increases as the second supplier's share of GHG reduction costs increases 714 in the fourth scenario. The reduction of GHG emissions increases the manufacturer's non715 production costs, and the manufacturer seeks to compensate for the loss by increasing the prices 716 of its products, which leads to a slight decrease in the demand for them. The suppliers reduce their 717 raw material prices by reducing product demand, and the suppliers' profits decrease as raw material 718 prices and product demand are reduced according to Table (5). The decrease in the second 719 supplier's profit is much greater than that for the first supplier because there is an increase in cost 720 as well as a decrease in revenue. Besides, the total profit of the supply chain decreases with an 721 increase in the second supplier's share of the cost of reducing GHG emissions. The above share is 722 not economical for the supply chain in the fourth scenario but leads to a drastic decrease in GHG 723 emission and is environmentally friendly. According to Table (6), the demand for the second 724 product decreases in the fifth scenario with an increase in the second supplier's share of the cost of 725 reducing GHG emission, as in the fourth scenario, but the demand for the first product remains constant. Table (7) shows that the coalition members increase their profits by increasing the prices 727 of the products, and the profit of the second supplier decreases as the demand for the second product decreases. A sharp decline in the profit of the second supplier causes a decrease in the total profit of the supply chain, with an increase in the parameter. The reduction of GHG emissions in the fifth scenario is close to that in the centralized scenario, and the second supplier's profit decline is not severe where it has a 0.2 share of the coalition members' costs of reducing GHG emissions,

732 which allows it to approach the ideal environmental goal of the sustainable supply chain, with an 733 insignificant rate of decline in profit.

Table (4) Optimal values of the variables in the fourth scenario

\begin{tabular}{cccccccc}
\hline$\rho$ & $x$ & $p_{1}$ & $p_{2}$ & $d_{1}$ & $d_{2}$ & $w_{1}$ & $w_{2}$ \\
\hline 0.1 & 239.95 & 74.77 & 62.57 & 90274.93 & 73342.60 & 13.046 & 10.435 \\
0.2 & 267.48 & 74.99 & 62.77 & 90079.99 & 72246.55 & 13.019 & 10.421 \\
0.3 & 302.22 & 75.26 & 63.03 & 89838.34 & 72127.877 & 12.984 & 10.404 \\
0.4 & 347.48 & 75.606 & 63.36 & 89531.42 & 71975.54 & 12.94 & 10.382
\end{tabular}

Table (5) Optimal values of the supply chain members' objective functions in the fourth scenario

\begin{tabular}{ccccc}
\hline$\rho$ & $Z_{S_{1}}$ & $Z_{S_{2}}$ & $Z_{M}$ & $Z_{M}+Z_{S_{1}}+Z_{S_{2}}$ \\
\hline 0.1 & 1164223.419 & 740150.874 & 9060027.416 & 10964400 \\
0.2 & 1159200 & 727052.089 & 9076883.911 & 10963140 \\
0.3 & 1152989.679 & 707582.635 & 9098291.28 & 10958860 \\
0.4 & 1145125.046 & 677282.252 & 9126463.43 & 10948870 \\
\hline
\end{tabular}


Table (6) Optimal values of the variables in the fifth scenario

\begin{tabular}{ccccccc}
\hline$\rho$ & $x$ & $p_{1}$ & $p_{2}$ & $d_{1}$ & $d_{2}$ & $w_{1}$ \\
\hline 0.1 & 850.08 & 58.35 & 55.73 & 200000 & 86213.32 & 12.42 \\
0.2 & 941.28 & 58.89 & 56.24 & 200000 & 86540 & 12.46 \\
0.3 & 1020.75 & 59.47 & 56.92 & 200000 & 85547.82 & 12.31 \\
0.4 & 1119.43 & 60.18 & 57.75 & 200000 & 82255.05 & 12.14 \\
\hline
\end{tabular}

737

738

739

740

741

742

743

744

745

746

747

748

749

750

751

752

753

754

755

756

757

758

759

Table (7) Optimal values of the supply chain members' objective functions in the fifth scenario

\begin{tabular}{cccc}
\hline$\rho$ & $Z_{S_{2}}$ & $Z_{M}+Z_{S_{1}}$ & $Z_{M}+Z_{S_{1}}+Z_{S_{2}}$ \\
\hline 0.1 & 967877.384 & 14268476.93 & 15236530 \\
0.2 & 839529.739 & 14374099.58 & 15213630 \\
0.3 & 636935.772 & 14504220.88 & 15141160 \\
0.4 & 362501.206 & 14677428.57 & 15029930 \\
\hline
\end{tabular}

\subsection{Effect of the manufacturer's budget}

To investigate the effect of the budget parameter, it is assumed to vary from 1000000 to 3000000 .

The cost of reducing GHG emissions is higher than the other production costs, so the manufacturer and coalition members seek to reduce GHG emissions by increasing the budget to increase demand and profit. The pricing strategy of the supply chain members varies as the budgets for different products and scenarios increase. According to Figures (2a) to (2d), the manufacturer and coalition members seek to increase demand by reducing the price of the second product in all the scenarios and of the first product in the second and fourth scenarios. In the first, third, and fifth scenarios, the manufacturer cannot increase the demand for the first product due to the limited supply capacity for the raw materials of the first product and seeks to maximize profit by increasing price. According to Figure (2f), the total profit of the supply chain also increases in all the scenarios with an increase in the budget. The suppliers can increase the profits of the supply chain members and the total supply of the supply chain by increasing supply capacity where the supply chain members form the coalitions. The reduction of GHG emissions as the budget increases is greater in the third and fifth scenarios than in the second and fourth because price competition is less severe in the former scenarios. The rate of increase in total supply chain profit is higher in the second and fourth scenarios than in the others because customer demand is less in these scenarios due to price competition, and supply capacity limitations do not prevent the increase in the chain members' profits. It is economical to increase the budget in the scenarios where the supply chain members compete, and it is environment-friendly where they form alliances. 


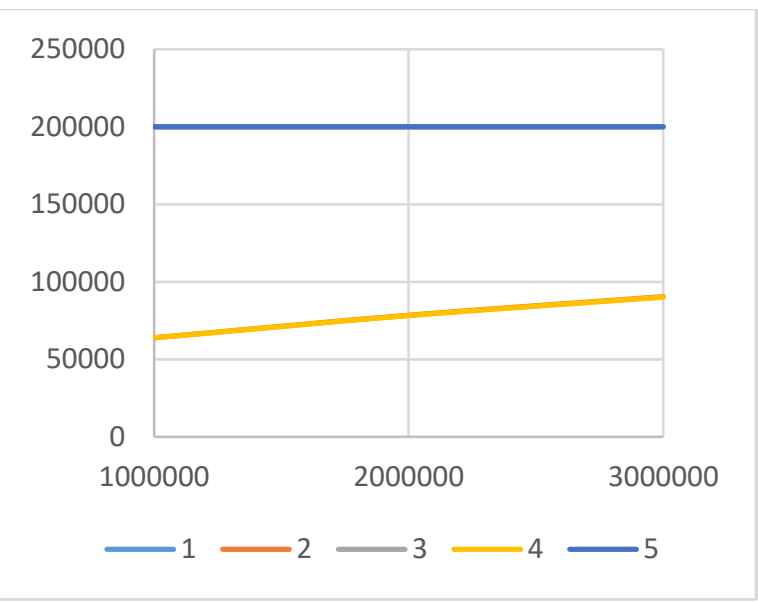

(a)

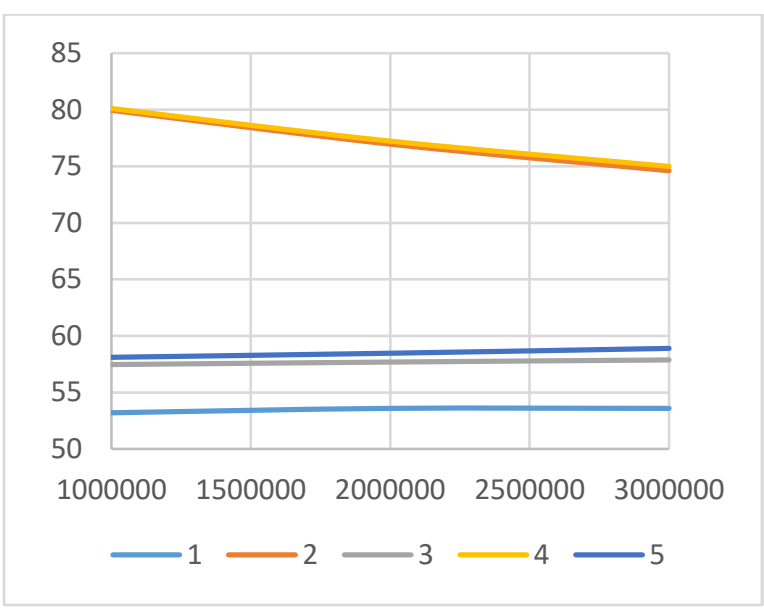

(c)

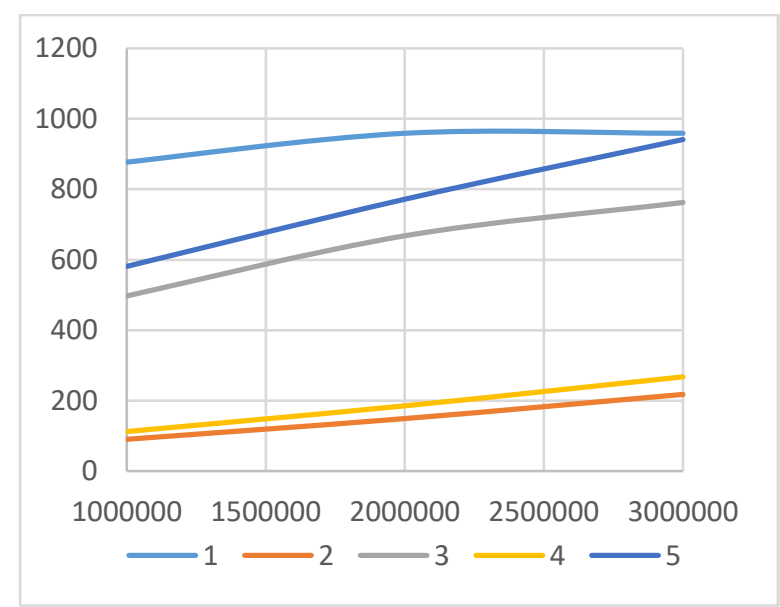

(e)

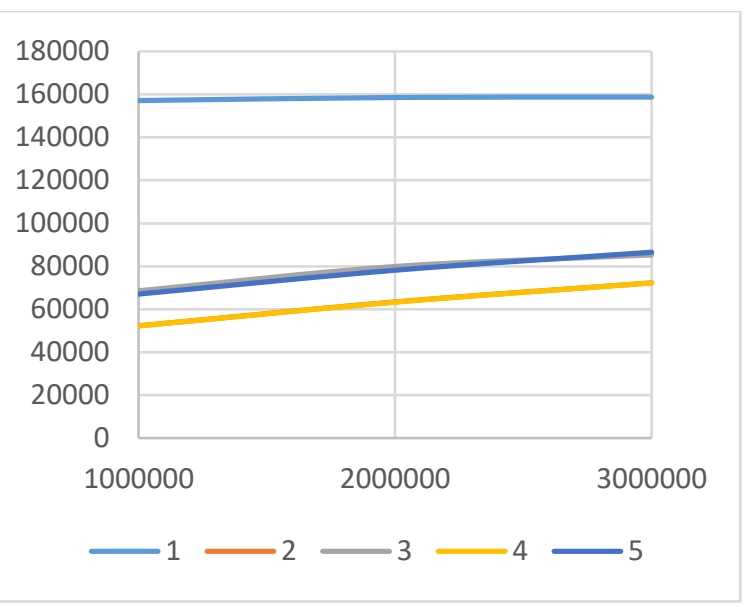

(b)

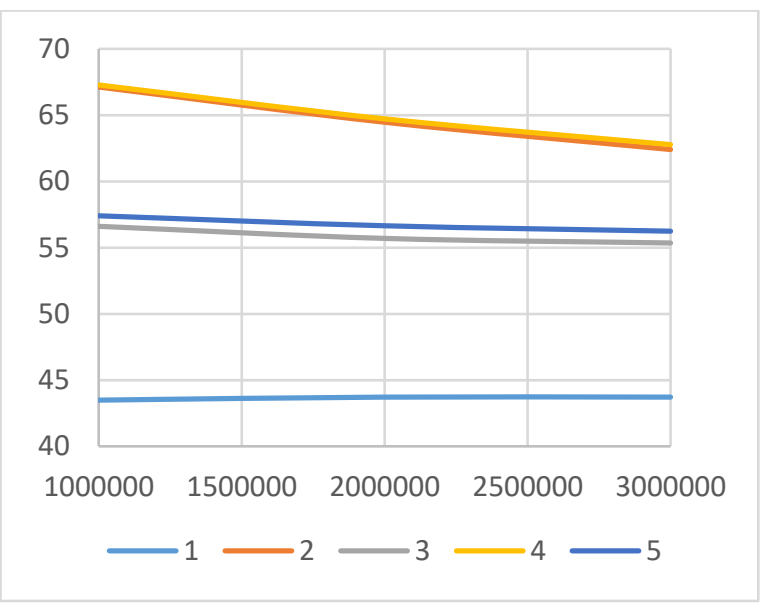

(d)

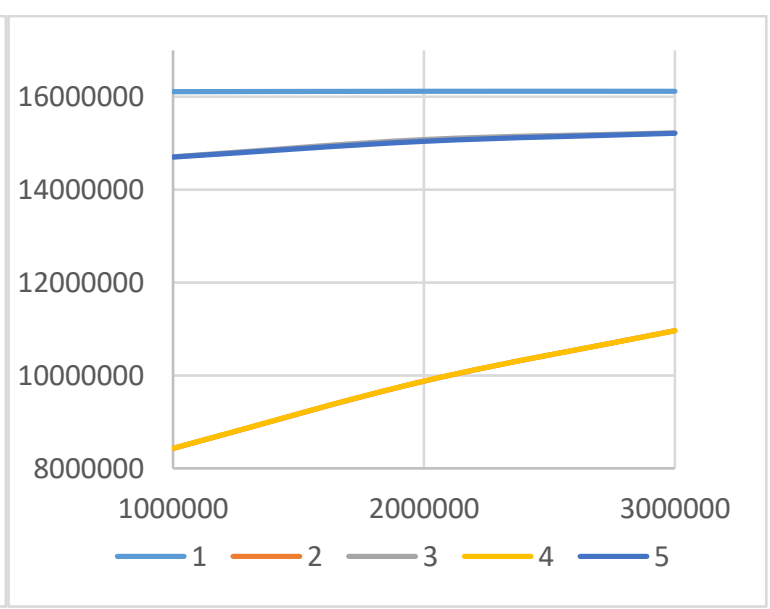

(f)

766 Figure (2) Effects of $\boldsymbol{B}$ on a) demand for the first product, b) demand for the second product, c) price of the 767 first product, d) price of the second product, e) reduction of GHG emission, and f) supply chain profit. 


\subsection{Effect of the manufacture's capacity}

769 The value of the parameter is assumed to lie between 120000 and 360000, and we can analyze its

770

771

772

773

774

775

776

777

778

779

780

781 effect by considering the values of the other parameters as constant. The supply chain members seek to reduce the price to increase demand by raising production capacity according to Figures (3a) to (3d). The rate of price reduction is less in the second and fourth scenarios than in the others because there is severer competition for price in these scenarios. The competitive supply chain members cannot drastically reduce the product prices, so they decrease the cost of reducing GHG emissions by increasing them as shown in Figure (3e). GHG emissions decrease as production capacity increases in the first, third, and fifth scenarios, and they increase in the second and fourth scenarios. It is environment-friendly for the supply chain members who have formed coalitions to increase production capacity. According to Figure (3-f), the total profit of the supply chain increases in all the scenarios as supply capacity increases. The increase in the total profit of the supply chain is far greater in the first, third, and fifth scenarios than in the other two, so the increase in capacity is more economical in the scenarios where the supply chain members form alliances.

\subsection{Effect of the cost of reducing GHG emission}

We study the effects of the cost of reducing GHG emissions by having the value of the parameter range from 0.8 to 1.3. According to Figure (4e), GHG emission increases in all the scenarios with the increasing cost of reducing GHG emissions. The increase in GHG emission is greater in the first, third, and fifth scenarios than in the other two, so the increase in the cost of reducing GHG has a worse effect in terms of environmental goals for the supply chain members that form the coalition. Figures (4a) to (4d) show that the supply chain members cannot invest in reducing GHG emissions for all the scenarios due to increased cost. They determine a lower price to prevent a sharp decline in customer demand. Supply chain profit decreases in all the scenarios with the increase in the cost of reducing GHG emissions, according to Figure (4f). The total profit of the supply chain is higher in the fifth scenario than in the third, where $r$ is less than one, and it is higher in the fourth scenario than in the second. The second supplier's share of the cost of reducing GHG is economical, where the cost is less than one, so the supplier's decision to share the cost with the manufacturer depends on the amount. 


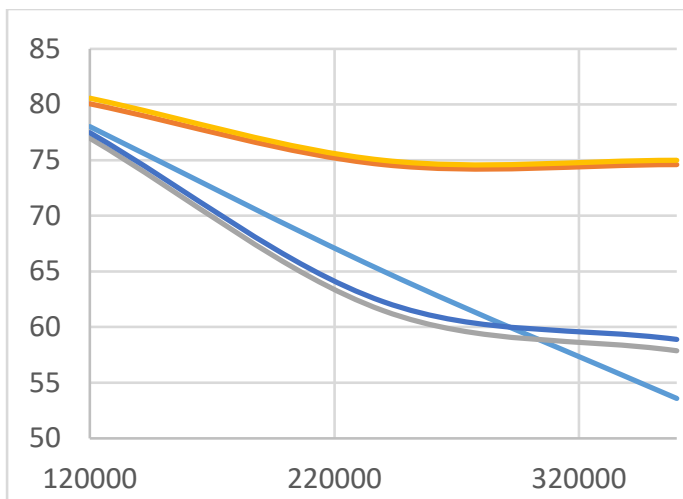

$1-2-3-5$ (a)

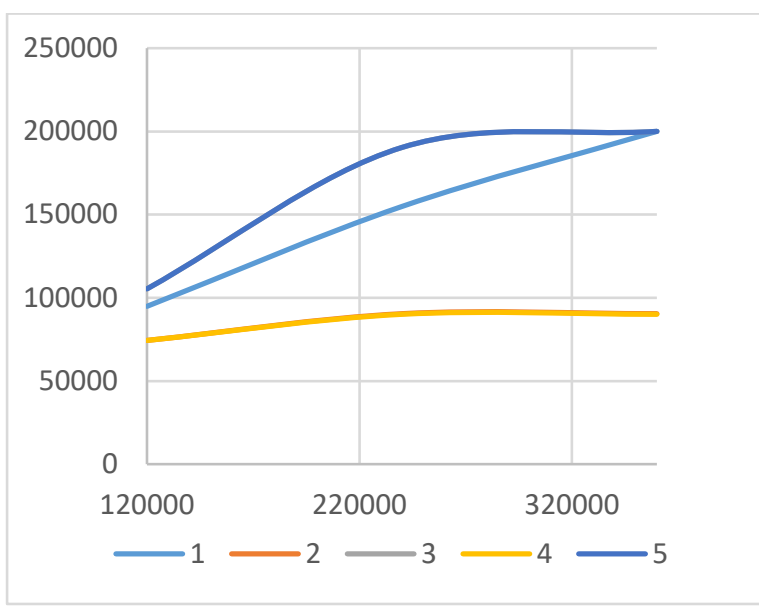

(c)

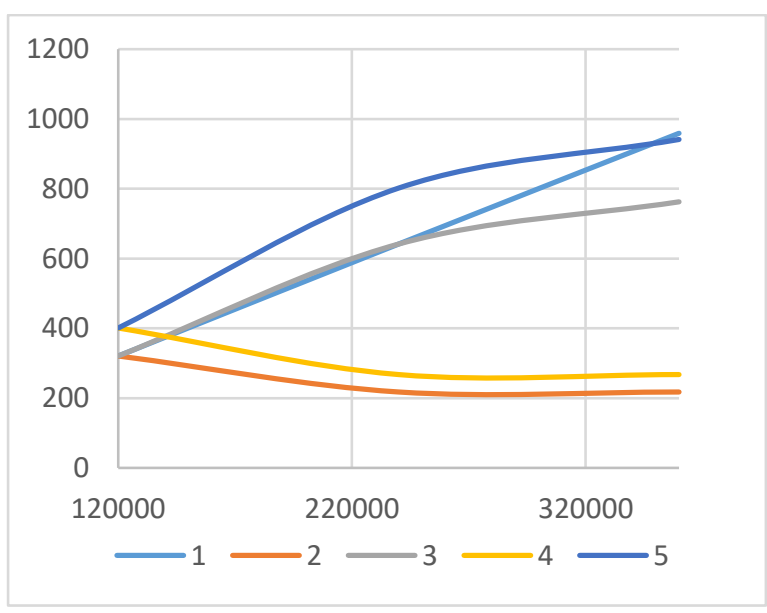

(e)

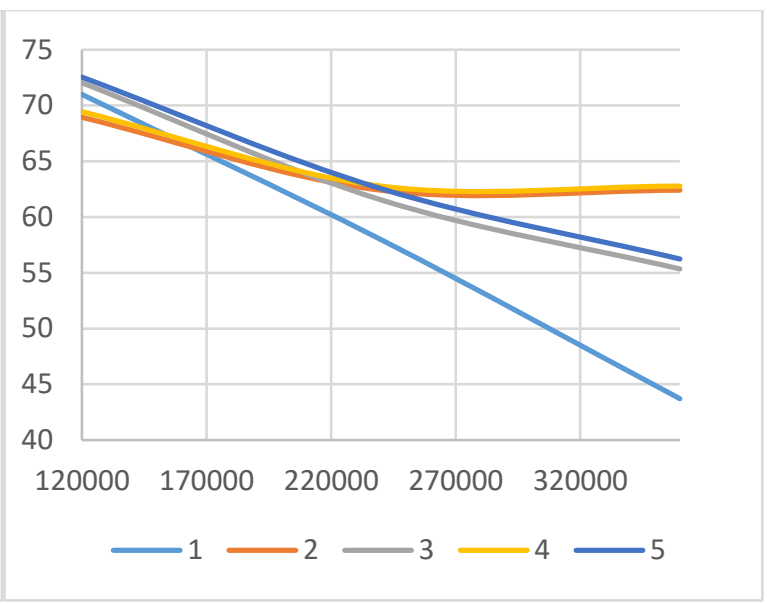

(b)

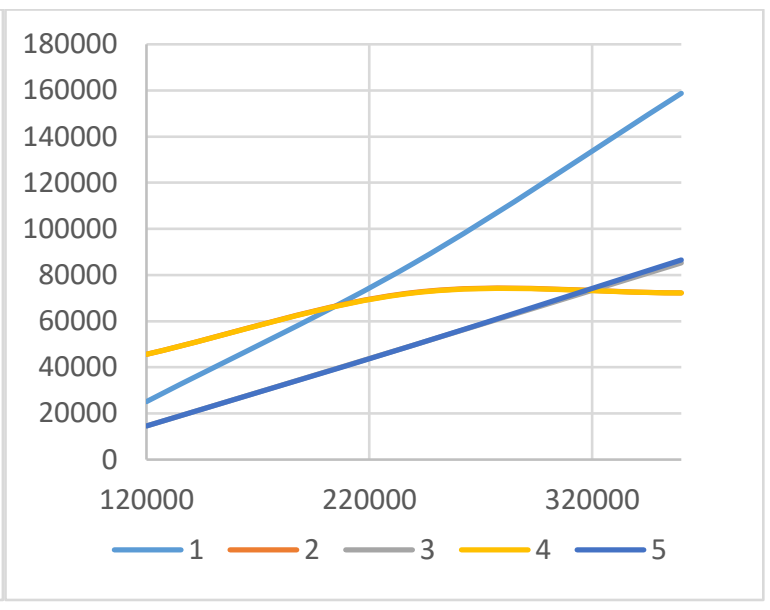

(d)

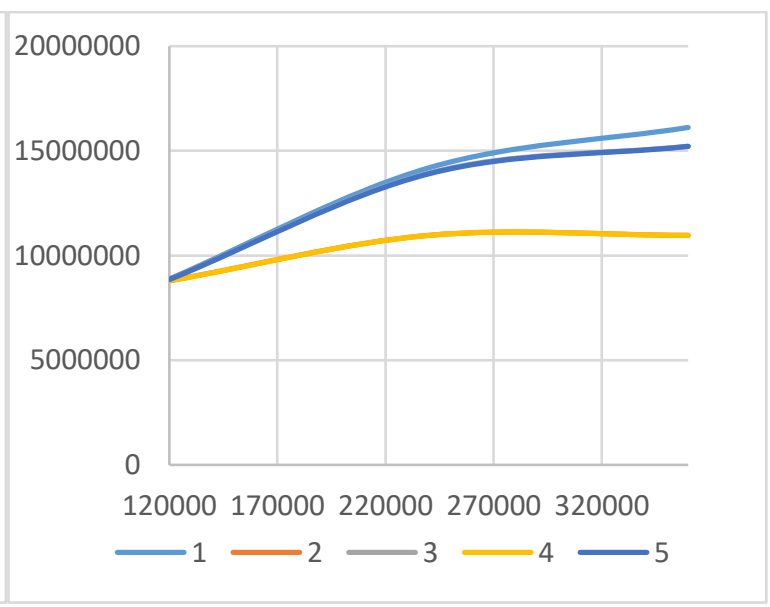

(f)

803 Figure (3) Effects of $\boldsymbol{\tau}$ on a) price of the first product, b) price of the second product, c) demand for the first 804 


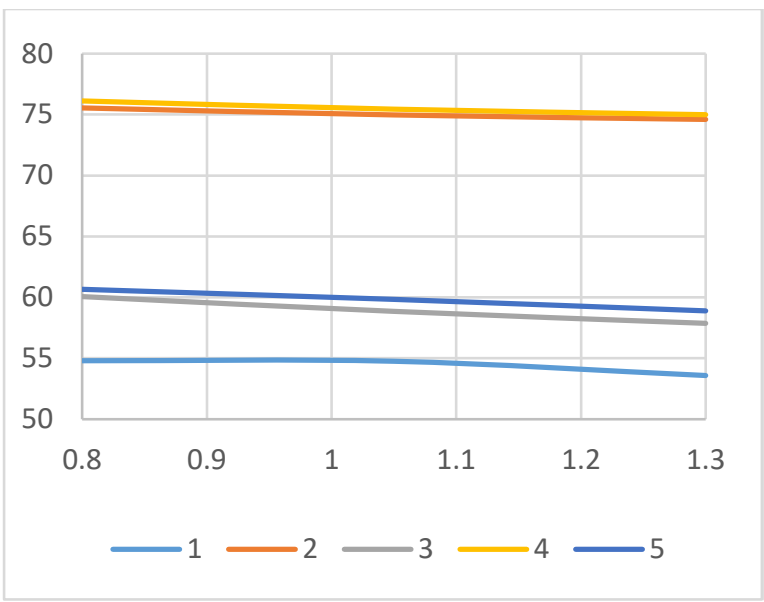

(a)

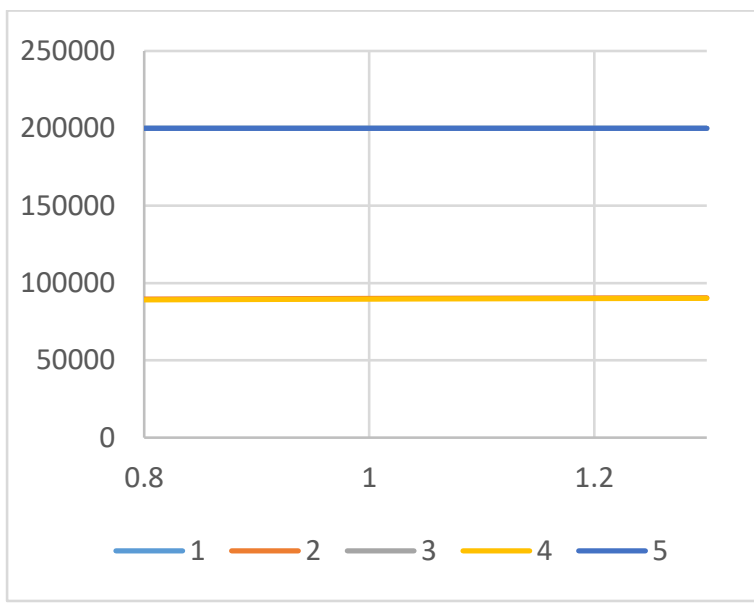

(c)

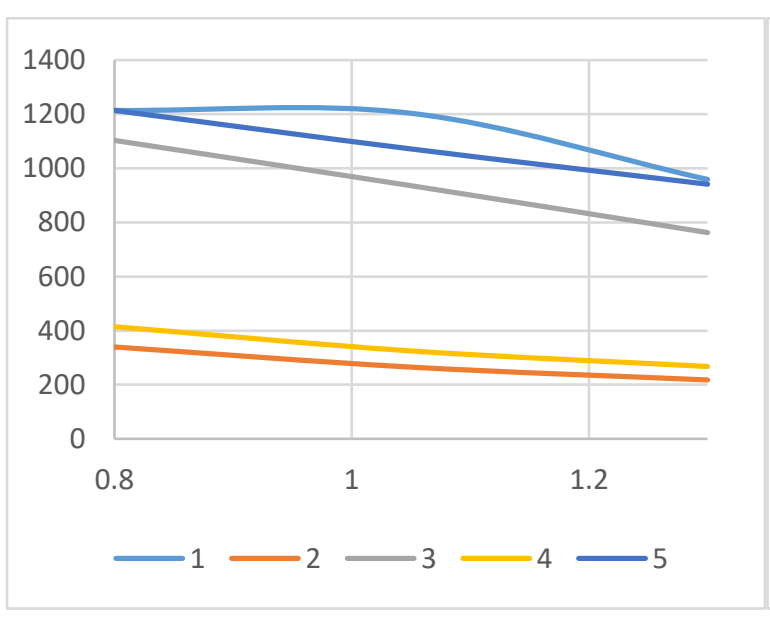

(e)

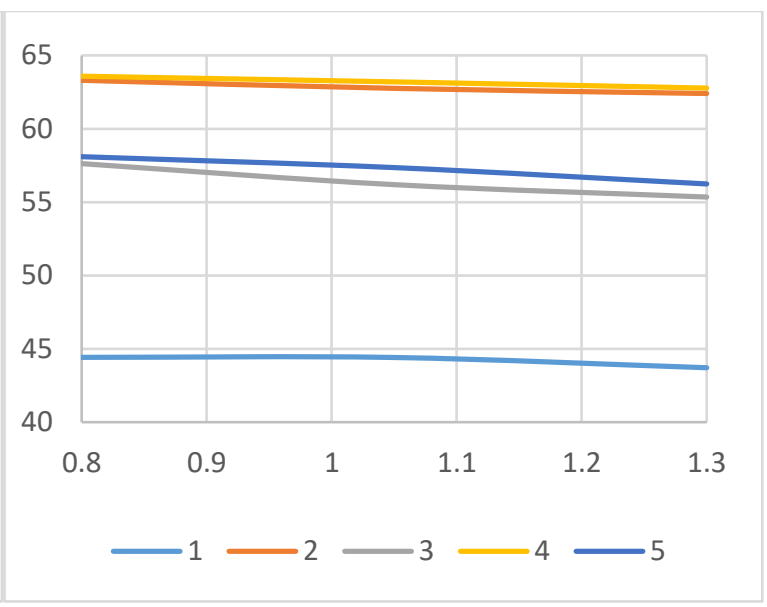

(b)

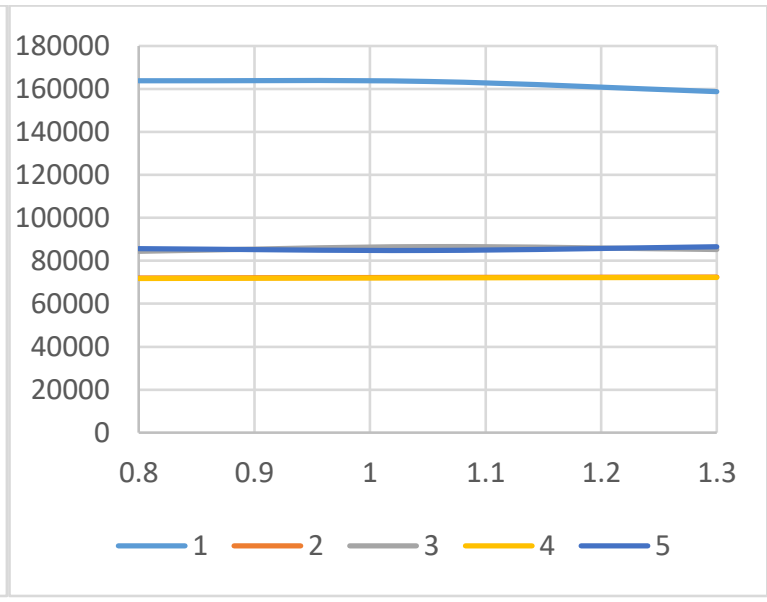

(d)

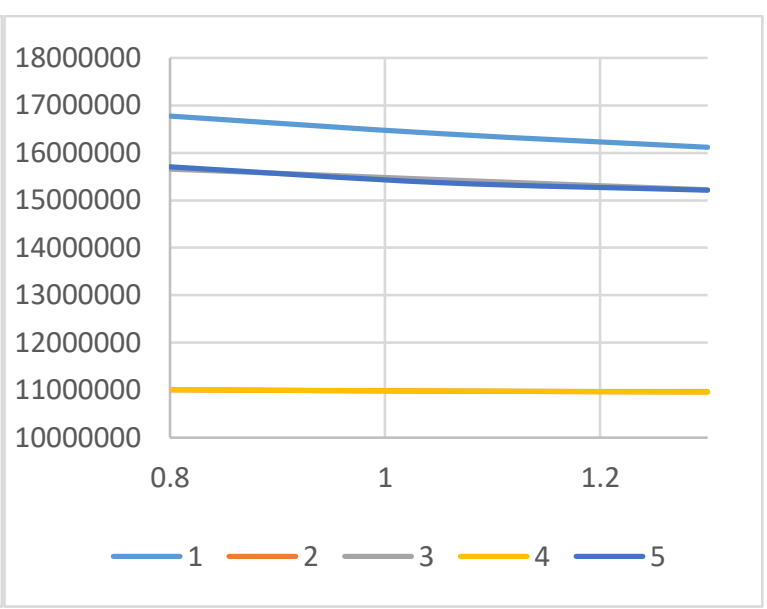

(f)

811 Figure (4) Effects of $\boldsymbol{r}$ on a) price of the first product, b) price of the second product, c) demand for the first product, d) demand for the second product, e) reduction of GHG emissions, and f) supply chain profit. 


\subsection{Effect of government penalty on the endangerment of consumer health}

814 According to Table (8), more fines are required for the coalition members' failure to use melamine 815 in the third and fifth scenarios than in the second and fourth, so consumers are more likely to be 816 endangered in the former scenarios. There is severer competition over price between the supply 817 chain members in the second and fourth scenarios, and the manufacturer costs increase with an 818 increase in the penalty parameter, so the manufacturer does not use melamine to prevent a decrease 819 in demand. In these scenarios, the manufacturer prefers not to use melamine rather than to reduce price and increase GHG emissions to maintain the demand for the first product and increase that of the second product according to Figures (5- a) to (5-e). The percentages of melamine used in

822 the third and fifth scenarios for different values of parameter $g$ are higher than those for the second and fourth scenarios. Figures (5-a) to (5-e) show that the coalition members prefer to use melamine and reduce product price and GHG emissions to maintain the demand for the first product and increase that of the second product. The optimal values of the variables remain constant with an increase in the parameter in the second and fourth scenarios, so the total profit of the supply chain is constant in these scenarios as shown in Figure (5-f). In the centralized scenario, the decisionmaker reduces the optimal value of melamine by increasing parameter $g$, seeking to prevent a decline in demand by reducing price and GHG emissions according to Figures (5-a) to (5-e), but these changes do not reduce the total profit of the supply chain as shown in Figure (5-f). An interesting result is obtained for the third and fifth scenarios, where total supply chain profit increases with an increase in the parameter. The demand for the second product increases with lower prices and less GHG emission and melamine use. The increase in demand leads to an increase in the total profit of the supply chain according to Figure (5-f). Total supply chain profit is higher in the fifth scenario than in the third, where $g$ is less than 230 .

Table (8) Optimal percentage of additives for different values of $\boldsymbol{g}$

\begin{tabular}{cccccc}
\hline$g$ & First Scenario & Second Scenario & Third Scenario & Fourth Scenario & Fifth Scenario \\
\hline 210 & 0.0001 & $1.72 \times 10^{-8}$ & $7.98 \times 10^{-5}$ & 0 & $4.82 \times 10^{-5}$ \\
220 & 0.0001 & 0 & $5.78 \times 10^{-5}$ & 0 & $2.49 \times 10^{-5}$ \\
230 & $9.8 \times 10^{-5}$ & 0 & $3.75 \times 10^{-5}$ & 0 & $2.65 \times 10^{-6}$ \\
240 & 0 & 0 & 0 & 0 & 0 \\
\hline
\end{tabular}



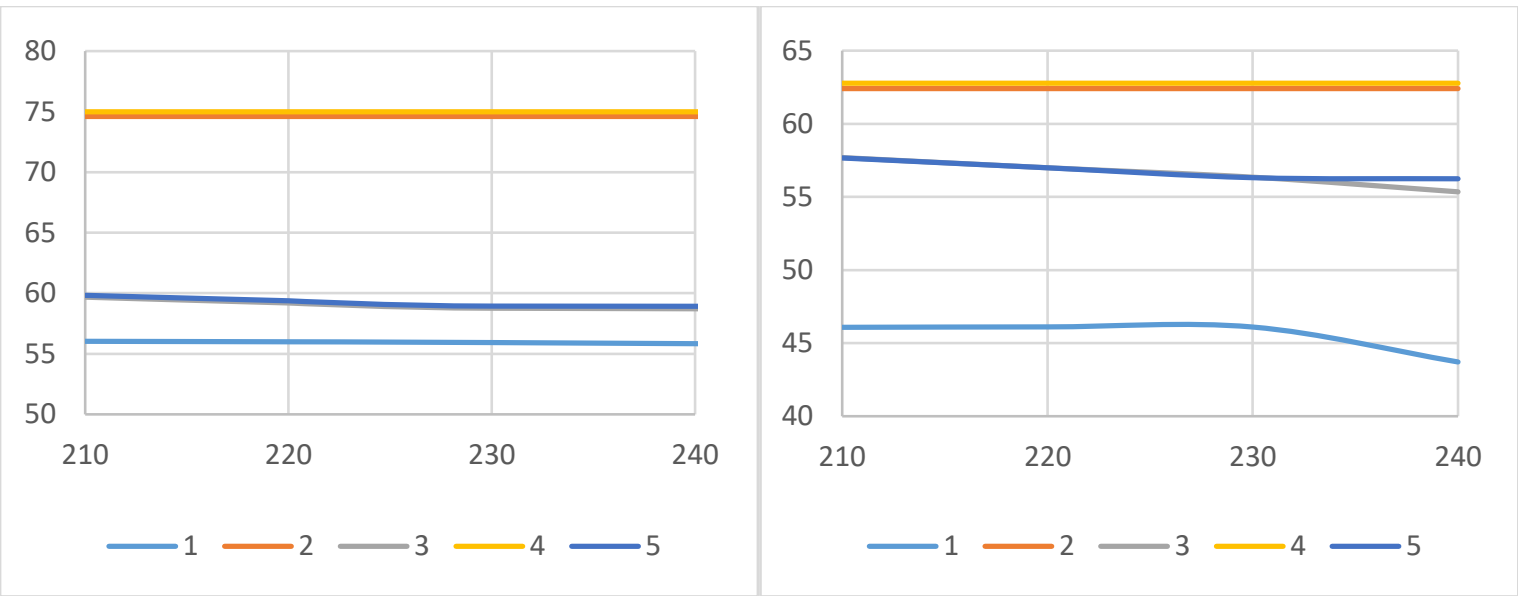

(a)

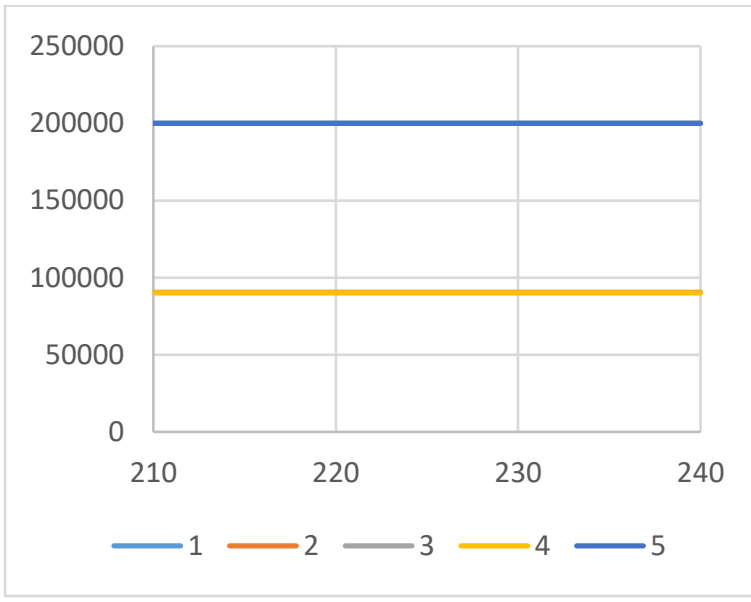

841 (c)

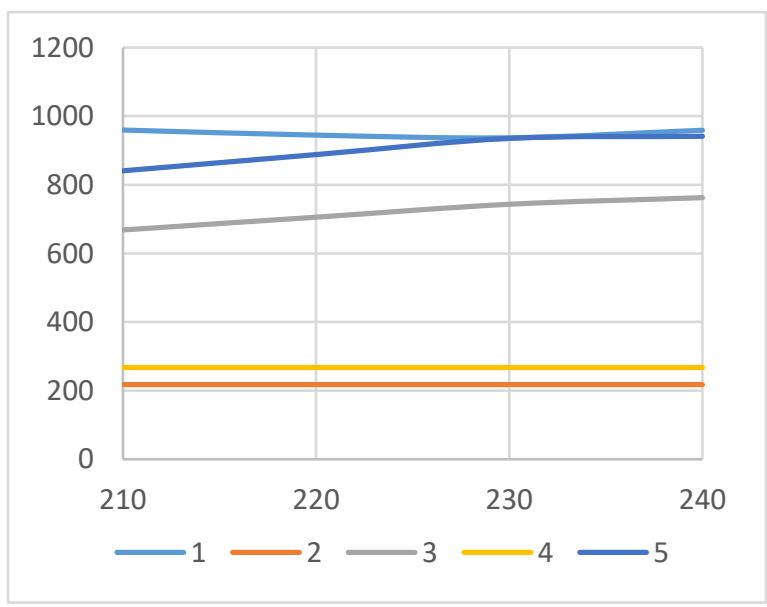

(e) (b)

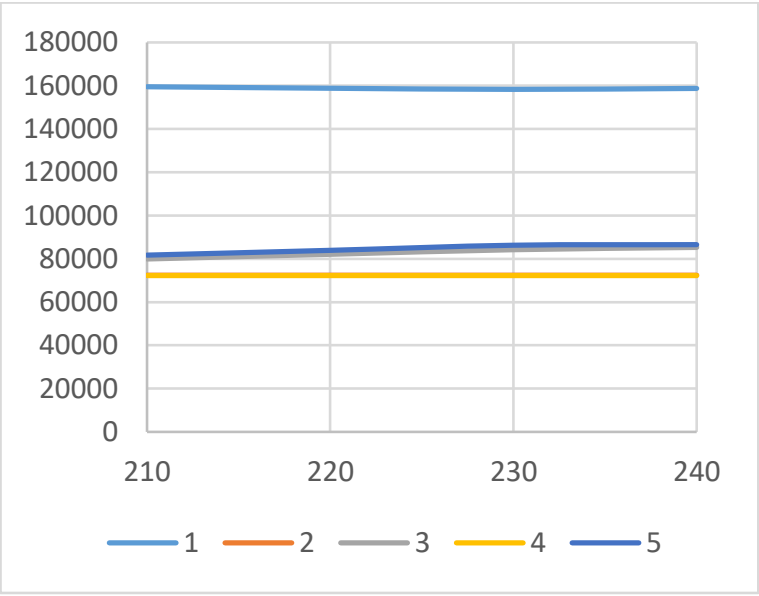

(d)

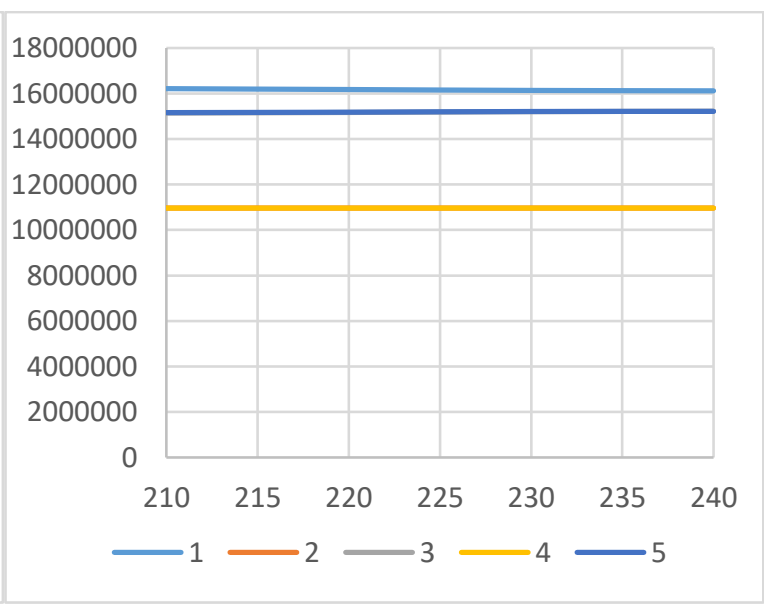

(f)

Figure (5) Effects of $g$ on a) price of the first product, b) price of the second product, c) demand for the first product, d) demand for the second product, e) reduction of GHG emissions, and f) supply chain profit. 


\section{Conclusion}

847 The food industry is one where consumer demand is constantly increasing, so companies must meet customers' new needs to maintain their competitive market positions. Today, quality and sustainability are among the main criteria for customers to buy food products. In this paper, it is assumed that the manufacturer reduces GHG emissions from the production process to increase customer demand. The reduction of greenhouse gas emissions increases manufacturer costs. Manufacturers use additives to reduce costs and increase demand, which may be detrimental to consumer health. The government imposes fines on the manufacturer for the use of additives to protect consumer health. All three dimensions of the sustainable supply chain are investigated for the problem addressed in this paper. Centralized and decentralized structures for the supply chain are studied, including one manufacturer and two suppliers. The goal of the centralized supply chain in the first model is to maximize total supply chain profit. Decentralized structures are considered for the supply chain in other scenarios. In the second scenario, the supply chain members compete to maximize profit. The manufacturer and the first supplier form an alliance in the third scenario. The second supplier shares the cost of reducing GHG emissions in the fourth scenario. The first supplier allies with the manufacturer, and the second one shares the cost of reducing GHG emissions in the fifth scenario. The first model is solved as a single-level model, and bi-level programming is used to model the other scenarios.

864

The above five scenarios have been solved for a numerical example, and the results demonstrate that the total profit of the supply chain in the third scenario is the greatest among those in the decentralized scenarios, and GHG emissions are least in the fifth scenario among the decentralized scenarios. It is economical to increase the budget in the scenarios where the supply chain members compete. Moreover, it is environment-friendly to increase production capacity and the budget for the supply chain members that have formed coalitions. The difference between the total profits of the supply chain in the third and fifth scenarios is less than that between the GHG emissions in the two scenarios, so the fifth scenario is appropriate for the achievement of a balance between the economic and environmental goals of the sustainable supply chain, as compared to the other decentralized structures. The total profits of the supply chain in the fourth and fifth scenarios decrease as the second supplier's share of the cost of reducing GHG emission increases. The amount of reduction of GHG emissions in the fifth scenario is close to the value of the variable in the centralized scenario, and the second supplier's profit decline is not severe, where the second supplier has a 0.2 share of the cost of reducing GHG emissions. The total profit of the supply chain in the fifth scenario is higher than that in the third scenario where $r$ is less than one, and the total profit of the supply chain in the fourth scenario is higher than that in the second scenario under the same conditions. Consumer health is at higher risk in the first, third, and fifth scenarios than in the others. Uncertainty and risk management have gained plenty of significance in the food supply chain, so these issues should be considered in future research on the food supply chain. 
Furthermore, different criteria can be considered for the environmental and social dimensions of the food supply chain.

\section{References}

Ahumada, O., Villalobos, J.R., 2009. Application of planning models in the agri-food supply chain: A review. European journal of Operational research 196(1), 1-20.

Food, U., Organization, A., 2010. Greenhouse Gas Emissions from the Dairy Sector. A Life Cycle Assessment.

Gillingham, K., Stock, J.H., 2018. The cost of reducing greenhouse gas emissions. Journal of Economic Perspectives 32(4), 53-72.

Golpîra, H., Najafi, E., Zandieh, M., Sadi-Nezhad, S., 2017. Robust bi-level optimization for green opportunistic supply chain network design problem against uncertainty and environmental risk. Computers \& Industrial Engineering 107, 301-312.

Govindan, K., Jafarian, A., Khodaverdi, R., Devika, K., 2014. Two-echelon multiple-vehicle location-routing problem with time windows for optimization of sustainable supply chain network of perishable food. International Journal of Production Economics 152, 9-28.

Hafezalkotob, A., 2017. Competition, cooperation, and coopetition of green supply chains under regulations on energy saving levels. Transportation Research Part E: Logistics and Transportation Review 97, 228-250.

Ji, J., Zhang, Z., Yang, L., 2017. Carbon emission reduction decisions in the retail-/dual-channel supply chain with consumers' preference. Journal of Cleaner Production 141, 852-867.

Jian, M., He, H., Ma, C., Wu, Y., Yang, H., 2019. Reducing greenhouse gas emissions: a duopoly market pricing competition and cooperation under the carbon emissions cap. Environmental Science and Pollution Research 26(17), 16847-16854.

Kirilova, E.G., Vaklieva-Bancheva, N.G., 2017. Environmentally friendly management of dairy supply chain for designing a green products' portfolio. Journal of Cleaner Production 167, 493504.

Kuhn, M., 2006. The karush-kuhn-tucker theorem. Mannheim, Germany, CDSEM Uni Mannheim. Li, X., Zhou, K., 2021. Multi-objective cold chain logistic distribution center location based on carbon emission. Environmental Science and Pollution Research, 1-9.

Mahmoodi, A., 2019. Joint pricing and inventory control of duopoly retailers with deteriorating items and linear demand. Computers \& Industrial Engineering 132, 36-46.

Manteghi, Y., Arkat, J., Mahmoodi, A., Farvaresh, H., 2020. Competition and cooperation in the sustainable food supply chain with a focus on social issues. Journal of Cleaner Production, 124872. Martínez-Guido, S.I., González-Campos, J.B., Ponce-Ortega, J.M., 2018. A Multi-Stakeholder Optimization of Food Supply Chains: an Undernourishment Reduction Strategy. Process Integration and Optimization for Sustainability 2(3), 239-257.

Matsumoto, A., Szidarovszky, F., 2016. Game theory and its applications. Springer.

Peng, B., Wang, Y., Elahi, E., Wei, G., 2019. Behavioral game and simulation analysis of extended producer responsibility system's implementation under environmental regulations. Environmental Science and Pollution Research 26(17), 17644-17654.

Raj, A., Biswas, I., Srivastava, S.K., 2018. Designing supply contracts for the sustainable supply chain using game theory. Journal of cleaner production 185, 275-284. 
Rohmer, S., Gerdessen, J.C., Claassen, G., 2019. Sustainable supply chain design in the food system with dietary considerations: A multi-objective analysis. European Journal of Operational Research 273(3), 1149-1164.

Safaei, A.S., Farsad, S., Paydar, M.M., 2018. Robust bi-level optimization of relief logistics operations. Applied Mathematical Modelling 56, 359-380.

Saranwong, S., Likasiri, C., 2017. Bi-level programming model for solving distribution center problem: a case study in Northern Thailand's sugarcane management. Computers \& Industrial Engineering 103, 26-39.

Sarkar, S., Bhadouriya, A., 2020. Manufacturer competition and collusion in a two-echelon green supply chain with production trade-off between non-green and green quality. Journal of Cleaner Production, 119904.

Sharif, N.S., Pishvaee, M.S., Aliahmadi, A., Jabbarzadeh, A., 2018. A bi-level programming approach to joint network design and pricing problem in the municipal solid waste management system: A case study. Resources, Conservation and Recycling 131, 17-40.

Shirzadi, S., Ghezavati, V., Tavakkoli-Moghaddam, R., Ebrahimnejad, S., 2021. Developing a green and bipolar fuzzy inventory-routing model in agri-food reverse logistics with postharvest behavior. Environmental Science and Pollution Research, 1-18.

Song, C., Zhuang, J., 2017. Modeling a government-manufacturer-farmer game for food supply chain risk management. Food control 78, 443-455.

Song, C., Zhuang, J., 2018. Regulating food risk management - a government-manufacturer game facing endogenous consumer demand. International Transactions in Operational Research 25(6), 1855-1878.

Tabrizi, S., Ghodsypour, S.H., Ahmadi, A., 2018. Modelling three-echelon warm-water fish supply chain: A bi-level optimization approach under Nash-Cournot equilibrium. Applied Soft Computing 71, 1035-1053.

Wang, M., Zhang, R., Zhu, X., 2017. A bi-level programming approach to the decision problems in a vendor-buyer eco-friendly supply chain. Computers \& Industrial Engineering 105, 299-312. Wang, X., Li, D., 2012. A dynamic product quality evaluation based pricing model for perishable food supply chains. Omega 40(6), 906-917.

Xu, L., Wang, C., Miao, Z., Chen, J., 2019. Governmental subsidy policies and supply chain decisions with carbon emission limit and consumer's environmental awareness. RAIROOperations Research 53(5), 1675-1689.

Yu, M., Cruz, J.M., 2019. The sustainable supply chain network competition with environmental tax policies. International Journal of Production Economics 217, 218-231.

Yue, D., You, F., 2017. Stackelberg-game-based modeling and optimization for supply chain design and operations: A mixed integer bilevel programming framework. Computers \& Chemical Engineering 102, 81-95.

Zhang, J., Liu, G., Zhang, Q., Bai, Z., 2015. Coordinating a supply chain for deteriorating items with a revenue sharing and cooperative investment contract. Omega 56, 37-49.

Zhou, Y., Qin, F., 2015. A Review of Sustainable Supply Chain Management Based on Game Theory, 2015 International Conference on Advanced Manufacturing and Industrial Application. Atlantis Press.

Zhu, Q., Li, X., Zhao, S., 2018. Cost-sharing models for green product production and marketing in a food supply chain. Industrial Management \& Data Systems 118(4), 654-682.

Zhu, W., He, Y., 2017. Green product design in supply chains under competition. European Journal of Operational Research 258(1), 165-180. 


\section{Appendix (1)}

972 A non-empty, convex, closed solution space for the players is the first condition to obtain at least

973 one solution for the game between them (Mahmoodi, 2019; Matsumoto and Szidarovszky, 2016).

974 According to Relations (13) and (14), the problem constraints are linear for the suppliers, and the

975 solution space is non-empty and convex. The value of the product demand function is greater than

976 or equal to zero, so the product of the positive parameter by demand is also positive, and Relations

977 (24) and (25) are always valid for the problem. According to Relations (24) and (26), the price of

978 the first product is obtained based on the percentage of additives and reduction of GHG emission,

979 which are constrained by Relations (6) and (8), so the price of the first product is limited to the 980 range obtained in Relation (27). The same procedure is gone through for the price of the second 981 product, and Relation (28) is obtained according to Relation (25), limiting the price of the second 982 product to the range obtained in Relation (29). According to Relation (3), the price of each product 983 is greater than or equal to the price of the raw materials of each supplier $p_{i} \geq w_{i}$. It has been proven 984 that the product price variables are limited, so those involving the prices of raw materials are also 985 limited, and their solution space is therefore closed. It has been proven that the solution space for 986 the supplier variables is non-empty, convex, and closed, so the first condition has been proven to 987 be valid.

$$
\begin{aligned}
& 0 \leq \alpha d_{1}+\delta d_{2} \\
& 0 \leq \delta d_{1}+\alpha d_{2} \\
& p_{1} \leq \frac{(\alpha+\delta)(\beta x+\gamma \Delta)+\bar{d}\left(\alpha \mu_{1}+\delta \mu_{2}\right)}{\alpha^{2}-\delta^{2}} \\
& p_{1} \leq \frac{(\alpha+\delta)(\beta e+\gamma u)+\bar{d}\left(\alpha \mu_{1}+\delta \mu_{2}\right)}{\alpha^{2}-\delta^{2}} \\
& p_{2} \leq \frac{(\alpha+\delta)(\beta x+\gamma \Delta)+\bar{d}\left(\alpha \mu_{2}+\delta \mu_{1}\right)}{\alpha^{2}-\delta^{2}} \\
& p_{2} \leq \frac{(\alpha+\delta)(\beta e+\gamma u)+\bar{d}\left(\alpha \mu_{2}+\delta \mu_{1}\right)}{\alpha^{2}-\delta^{2}}
\end{aligned}
$$

As can be seen, each supplier's objective function is continuous with respect to the corresponding variable (raw material price). The second derivative of the objective function of each supplier is negative with respect to the wholesale price of its raw materials $\left(\frac{\partial^{2} z_{s_{i}}}{\partial w_{i}{ }^{2}}=-2 \alpha\right)$, so the objective function is concave. The supplier objective functions are continuous and concave, so the second and third conditions for the suppliers are valid to obtain at least one solution in the game between them. 


\section{Appendix (2)}

996 It has been proven in lemma (1) that the game between the suppliers has at least one solution. It is

997

998

999

1000

1001

1002

1003

1004

1005

1006

1007

1008 sufficient to demonstrate that the game is strictly concave diagonal to prove the uniqueness of the solution (Mahmoodi, 2019; Matsumoto and Szidarovszky, 2016). First, $A\left(w_{i}, r\right)$ is obtained for the suppliers according to Relation (30).

$$
\begin{aligned}
A\left(w_{i}, r\right)=\left(\begin{array}{l}
A_{1}\left(w_{i}, r\right) \\
A_{2}\left(w_{i}, r\right)
\end{array}\right)=\left(\begin{array}{l}
r_{1} \nabla_{1} Z_{S_{1}} \\
r_{2} \nabla_{2} Z_{S_{2}}
\end{array}\right) \\
\quad=\left(\begin{array}{l}
r_{1}\left(\mu_{1} \bar{d}+\beta x+\gamma \Delta+\alpha\left(c_{1}-v_{1}-2 w_{1}\right)+\delta\left(v_{2}+w_{2}\right)\right) \\
r_{2}\left(\mu_{2} \bar{d}+\beta x+\gamma \Delta+\alpha\left(c_{2}-v_{2}-2 w_{2}\right)+\delta\left(v_{1}+w_{1}\right)\right)
\end{array}\right)
\end{aligned}
$$

It must be demonstrated that $J\left(w_{i}, r\right)+J^{T}\left(w_{i}, r\right)$ is negative definite to prove that the game between the suppliers is strictly concave diagonal. $J\left(w_{i}, r\right)$ is Jacobin's matrix with respect to the $w_{i}$ variable for $A\left(w_{i}, r\right)$, as presented in Relation (31). We know that $-4 \alpha r_{1}$ is always smaller than zero, so the first condition for the matrix holds given Relation (32). The matrix determinant is calculated in Relation (33), and we know that $\alpha>\delta$ holds for the model. It can be concluded from Relation (34) that the determinant of the matrix is always positive, and the matrix is negative definite if parameters $r_{1}$ and $r_{2}$ are set to 1 . According to these relations, the matrix $J\left(w_{i}, r\right)+$ $J^{T}\left(w_{i}, r\right)$ is negative definite, and the game between the two suppliers is strictly concave diagonal, so it has a unique solution.

$$
\begin{gathered}
J\left(w_{i}, r\right)=\left(\begin{array}{ll}
\frac{\partial A_{1}\left(w_{i}, r\right)}{\partial w_{1}} & \frac{\partial A_{1}\left(w_{i}, r\right)}{\partial w_{1}} \\
\frac{\partial A_{2}\left(w_{i}, r\right)}{\partial w_{1}} & \frac{\partial A_{2}\left(w_{i}, r\right)}{\partial w_{2}}
\end{array}\right)=\left(\begin{array}{cc}
-2 \alpha r_{1} & \delta r_{1} \\
\delta r_{2} & -2 \alpha r_{2}
\end{array}\right) \\
J\left(w_{i}, r\right)+J^{T}\left(w_{i}, r\right)=\left(\begin{array}{cc}
-2 \alpha r_{1} & \delta r_{1} \\
\delta r_{2} & -2 \alpha r_{2}
\end{array}\right)+\left(\begin{array}{cc}
-2 \alpha r_{1} & \delta r_{2} \\
\delta r_{1} & -2 \alpha r_{2}
\end{array}\right) \\
=\left(\begin{array}{cc}
-4 \alpha r_{1} & \delta\left(r_{1}+r_{2}\right) \\
\delta\left(r_{1}+r_{2}\right) & -4 \alpha r_{2}
\end{array}\right) \\
\operatorname{det}\left(J\left(w_{i}, r\right)+J^{T}\left(w_{i}, r\right)\right)=16 r_{1} r_{2} \alpha^{2}-\delta^{2}\left(r_{1}+r_{2}\right)^{2} \\
\operatorname{det}\left(J\left(w_{i t}, r\right)+J^{T}\left(w_{i t}, r\right)\right)=16 \alpha^{2}-4 \delta^{2}
\end{gathered}
$$

\section{Appendix (3)}

1010 There is no difference between the solution spaces for the suppliers in the second and fourth scenarios, so the solution space is non-empty, convex, and closed for the suppliers in both scenarios. It can be seen from Relations (12) and (18) that the suppliers' objective functions are

1013 continuous. The second derivative of the objective function of each supplier is negative with 
1014 respect to the wholesale price of its raw materials $\left(\frac{\partial^{2} z_{S_{i}}}{\partial w_{i t}{ }^{2}}=-2 \alpha\right)$, so the objective function is concave, and the game between the suppliers has at least one solution.

\section{Appendix (4)}

1017 The approach adopted for proof in lemma (1) is repeated in this section. $A\left(w_{i}, r\right)$ is obtained for 1018 the fourth scenario in Relation (35) with the assumption $r_{1}, r_{2} \geq 0 . A\left(w_{i}, r\right)$ is the same for the second and fourth scenarios, so the matrix $J\left(w_{i}, r\right)+J^{T}\left(w_{i}, r\right)$ is negative definite. It can be concluded that the game between the suppliers in the fourth model is strictly concave diagonal and 1021 has a unique solution.

$$
\begin{array}{r}
A\left(w_{i}, r\right)=\left(\begin{array}{l}
A_{1}\left(w_{i}, r\right) \\
A_{2}\left(w_{i}, r\right)
\end{array}\right)=\left(\begin{array}{l}
r_{1} \nabla_{1} Z_{S_{1}} \\
r_{2} \nabla_{2} Z_{S_{2}}
\end{array}\right) \\
\quad=\left(\begin{array}{l}
r_{1}\left(\mu_{1} \bar{d}+\beta x+\gamma \Delta+\alpha\left(c_{1}-v_{1}-2 w_{1}\right)+\delta\left(v_{2}+w_{2}\right)\right) \\
r_{2}\left(\mu_{2} \bar{d}+\beta x+\gamma \Delta+\alpha\left(c_{2}-v_{2}-2 w_{2}\right)+\delta\left(v_{1}+w_{1}\right)\right)
\end{array}\right)
\end{array}
$$

1022

1023

1024

1025

1026

$$
\begin{aligned}
& w_{i}{ }^{*}=\frac{\left(2 \alpha^{2}\left(c_{i}-v_{i}\right)+\delta^{2} v_{i}+\delta\left(\mu_{3-i} \bar{d}+\Delta \gamma+\beta x\right)+\alpha\left(2 \mu_{i} \bar{d}+2 \Delta \gamma+\delta\left(c_{3-i}+v_{3-i}\right)+2 \beta x\right)\right)}{4 \alpha^{2}-\delta^{2}} \\
& \frac{\partial w_{i}}{\partial \alpha}=-\frac{\left(4 \alpha^{2}+\delta^{2}\right) U_{i}^{1}+4 \alpha \delta\left(\delta\left(c_{i}+v_{i}\right)+2\left(\Delta \gamma+\beta x+\mu_{3-i} \bar{d}\right)\right)}{\left(4 \alpha^{2}-\delta^{2}\right)^{2}} \\
& \frac{\partial w_{i}}{\partial \delta}=\frac{\left.4 \alpha^{3}\left(c_{3-i}+v_{3-i}\right)+\left(4 \alpha^{2}+\delta^{2}\right)\left(\Delta \gamma+\beta x+\mu_{3-i} \bar{d}\right)+4 \alpha^{2} \delta\left(c_{i}+v_{i}\right)+U_{i}^{2}\right)}{\left(4 \alpha^{2}-\delta^{2}\right)^{2}}
\end{aligned}
$$

1027 The numerators and denominators of both fractions are always positive according to Relations (37) 1028 and (38), so $\frac{\partial w_{i}}{\partial \alpha} \leq 0, \frac{\partial w_{i}}{\partial \delta} \geq 0$.

1029 The raw material price equilibrium is placed in the supplier demand and profit functions, and the 1030 first derivative of the profit function is obtained with respect to two parameters.

$$
\begin{aligned}
& \frac{\partial Z_{s_{i}}}{\partial \alpha}=\frac{\left(2 \alpha^{2}\left(c_{i}+v_{i}\right)-\delta\left(\mu_{3-i} \bar{d}+\Delta \gamma+\delta\left(c_{i}+v_{i}\right)+\beta x\right)-\alpha\left(\delta\left(c_{3-i}+v_{3-i}\right)+2\left(\mu_{i} \bar{d}+2 \Delta \gamma+2 \beta x\right)\right)\right) U_{i}^{3}}{\left(4 \alpha^{2}-\delta^{2}\right)^{3}} \\
& \frac{\partial Z_{s_{i}}}{\partial \delta}=-\frac{2 \alpha\left(2 \alpha^{2}\left(c_{i}+v_{i}\right)-\delta\left(\mu_{3-i} \bar{d}+\Delta \gamma+\delta\left(c_{i}+v_{i}\right)+\beta x\right)-\alpha\left(\delta\left(c_{3-i}+v_{3-i}\right)+2\left(\mu_{i} \bar{d}+2 \Delta \gamma+2 \beta x\right)\right)\right) U_{i}^{4}}{\left(4 \alpha^{2}-\delta^{2}\right)^{3}}
\end{aligned}
$$


1031 We know that $\alpha>\delta$, and the numerators of both fractions are negative according to Relations (39)

1032 and (40); therefore, $\frac{\partial Z_{s_{i}}}{\partial \alpha} \leq 0, \frac{\partial Z_{s_{i}}}{\partial \delta} \geq 0$.

$$
\begin{aligned}
& U_{i}^{1}=\delta\left(c_{3-i}+v_{3-i}\right)+2\left(\Delta \gamma+\beta x+\mu_{i} \bar{d}\right), U_{i}^{2} \\
& =\alpha \delta\left(\delta\left(c_{3-i}+v_{3-i}\right)+4\left(\Delta \gamma+\beta x+\mu_{i} \bar{d}\right)\right) \\
& U_{i}^{3}=\left(8 \alpha^{4}\left(c_{i}+v_{i}\right)+\delta^{3}\left(\Delta \gamma+\mu_{3-i} \bar{d}+\delta\left(c_{i}+v_{i}\right)+\beta x\right)+4 \alpha^{3}\left(\delta\left(c_{3-i}+v_{3-i}\right)\right.\right. \\
& \left.+2\left(\Delta \gamma+\mu_{i} \bar{d}+\beta x\right)\right) \\
& +3 \alpha \delta^{2}\left(\delta\left(c_{3-i}+v_{3-i}\right)+2\left(\Delta \gamma+\mu_{i} \bar{d}+\beta x\right)\right)+2 \alpha^{2} \delta\left(\delta\left(c_{i}+v_{i}\right)+6\left(\Delta \gamma+\mu_{3-i} \bar{d}\right.\right. \\
& +\beta x))( \\
& U_{i}^{4}=4 \alpha^{3}\left(c_{3-i}+v_{3-i}\right)+\delta^{2}\left(\Delta \gamma+\mu_{3-i} \bar{d}+\beta x\right)+4 \alpha^{2}\left(\Delta \gamma+\mu_{3-i} \bar{d}+\beta x+\delta\left(c_{i}\right.\right. \\
& \left.\left.+v_{i}\right)\right)+\alpha \delta\left(\delta\left(c_{3-i}+v_{3-i}\right)+4\left(\Delta \gamma+\mu_{i} \bar{d}+\beta x\right)\right)
\end{aligned}
$$

\section{Appendix (6)}

1034 The difference between the wholesale prices of raw materials is obtained in Relation (44).

$$
w_{2}-w_{1}=\frac{\bar{d}\left(-\mu_{1}+\mu_{2}\right)+\delta\left(v_{1}-v_{2}\right)+\alpha\left(-c_{1}+c_{2}+v_{1}-v_{2}\right)}{2 \alpha+\delta}
$$

1035

If $\frac{\bar{d}\left(\mu_{2}-\mu_{1}\right)+\alpha\left(c_{2}-c_{1}\right)}{\alpha+\delta} \geq v_{2}-v_{1}$, then $w_{2} \geq w_{1}$; otherwise, $w_{2}<w_{1}$.

1036 The difference in the demand for the products is obtained in Relation (45).

$$
d_{2}-d_{1}=\frac{\bar{d}\left(-\mu_{1}+\mu_{2}\right)+\delta\left(v_{1}-v_{2}\right)+(\alpha+\delta)\left(c_{1}-c_{2}+v_{1}-v_{2}\right)}{2 \alpha+\delta}
$$

1037

If $\frac{\bar{d}\left(\mu_{2}-\mu_{1}\right)}{\alpha+\delta}+c_{1}-c_{2} \geq v_{2}-v_{1}$, then $d_{2} \geq d_{1}$; otherwise, $d_{2}<d_{1}$.

\section{Appendix (7)}

1039 We obtain the first derivative of the profit function of the second supplier with respect to the price 1040 of raw materials and set it to zero, assuming sufficient capacity for the second supplier, and the 1041 equilibrium of the wholesale price of raw materials for the second product is obtained in Relation 1042 (46).

$$
w_{2}^{*}=\frac{\mu_{2} \bar{d}+\alpha c_{2}+\Delta \gamma+\delta p_{1}-\alpha v_{2}+\Delta \gamma}{2 \alpha}
$$




$$
\begin{aligned}
& \frac{\partial w_{2}}{\partial \alpha}=-\frac{\Delta \gamma+\mu_{2} \bar{d}+\delta p_{1}+\Delta \gamma}{2 \alpha^{2}} \\
& \frac{\partial w_{2}}{\partial \delta}=\frac{p_{1}}{2 \alpha}
\end{aligned}
$$

1043 The numerators and denominators of both fractions in Relations (47) and (48) are always positive, 1044 so $\frac{\partial w_{2}}{\partial \alpha} \leq 0, \frac{\partial w_{2}}{\partial \delta} \geq 0$.

1045 The equilibrium of the price of raw materials is placed in the demand and profit functions of the 1046 second supplier, and the first derivative of the profit of the second supplier is obtained with respect 1047 to two parameters.

$$
\begin{aligned}
\frac{\partial Z_{S_{2}}}{\partial \alpha} & =-\frac{\left(\Delta \gamma+\beta x+\mu_{2} \bar{d}+\delta p_{1}-\alpha\left(c_{2}+v_{2}\right)\right)\left(\Delta \gamma+\beta x+\mu_{2} \bar{d}+\delta p_{1}+\alpha\left(c_{2}+v_{2}\right)\right)}{4 \alpha^{2}} \\
\frac{\partial Z_{S_{2}}}{\partial \delta} & =\frac{p_{1}\left(\Delta \gamma+\mu_{2} \bar{d}+\delta p_{1}-\alpha\left(c_{2}+v_{2}\right)+\beta x\right)}{2 \alpha}
\end{aligned}
$$

1048 We know that $d_{2} \geq 0$, so $\Delta \gamma+\beta x+\mu_{2} \bar{d}+\delta p_{1}-\alpha\left(c_{2}+v_{2}\right) \geq 0$. The numerators and

1049 denominators of both fractions in Relations (49) and (50) are always positive, so $\frac{\partial Z_{S_{2}}}{\partial \alpha} \leq 0, \frac{\partial Z_{S_{2}}}{\partial \delta} \geq$ 10500.

1051 Appendix (8)

1052 The difference between the prices of the products is obtained in Relation (51).

$$
p_{1}-p_{2}=-\frac{\Delta \gamma+\mu_{2} \bar{d}+\delta p_{1}+\alpha\left(c_{2}-2 p_{1}+v_{2}\right)+\beta x}{2 \alpha}
$$

If $p_{1}(2 \alpha-\delta)-\alpha v_{2} \geq \mu_{2} \bar{d}+\beta x+\gamma \Delta+\alpha c_{2}$, then $p_{1} \geq p_{2}$; otherwise, $p_{1}<p_{2}$.

1054 The difference in the demand for the products is obtained in Relation (52).

$d_{2}-d_{1}=-\frac{\alpha^{2}\left(c_{2}-2 p_{1}+v_{2}\right)+\delta\left(\Delta \gamma+\beta x+\mu_{2} \bar{d}+\delta p_{1}\right)+\alpha\left(\Delta \gamma+\beta x+2 \mu_{1} \bar{d}-\mu_{2} \bar{d}+\delta\left(c_{2}-p_{1}+v_{2}\right)\right)}{2 \alpha}$

If $p_{1}(2 \alpha-\delta)(\alpha+\delta)-\alpha(\alpha-\delta) v_{2} \geq \epsilon$, then $d_{2} \geq d_{1}$; otherwise, $d_{2}<d_{1}$.

1056 where $\epsilon=\alpha^{2} c_{2}+(\alpha+\delta)(\beta x+\gamma \Delta)+\bar{d}\left(2 \mu_{1} \alpha+\mu_{2}(\alpha-\delta)\right)$. 


\section{Appendix (9)}

1060 Let us consider the following optimization problem.

$$
\begin{aligned}
& \operatorname{Max} f(x) \\
& \text { subject to } g_{i}(x) \geq 0 i=1, m \\
& h_{j}(x)=0 j=1, l
\end{aligned}
$$

1061 The Slater condition is valid for the problem if the objective functions and constraints are hyper1062 concave, and $\bar{x}$ is obtained such that $g_{i}(\bar{x})>0, h_{j}(\bar{x})=0$. The objective functions of the 1063 suppliers in the second to fifth scenarios are concave. All the constraints are linear, so they are 1064 both concave and convex. The percentage of additives and the reduction of GHG emissions are 1065 assumed to be zero in the above scenarios. The price of each product is calculated according to 1066 Relation (56), where $\varepsilon$ is a very small value. The demand for each product is $(\alpha-\delta) \varepsilon$ according to 1067 the prices, percentage of additives, and reduction of GHG emission. The capacity of each supplier $1068 s_{i}$ is set to a value greater than $(\alpha-\delta) \varepsilon$, so Relation (13) is inactive for the suppliers. Therefore, 1069 the Slater quality condition is valid, and the optimal values of the variables can thus be obtained 1070 as KKT conditions are set for the suppliers.

$$
p_{i}=\frac{\left(\alpha \mu_{i}+\delta \mu_{3-i}\right) \bar{d}}{\left(\alpha^{2}-\delta^{2}\right)}-\varepsilon \quad, \quad \forall i
$$

1071 